WHC-EP-0792

\title{
Purex Plant Comparison With 40 CFR 61, Subpart H, and Other Referenced Guidelines for the Product Removal (PR) (296-A-1) Stack
}

J. Lohrasbi

Westinghouse Hanford Company

Date Published

August 1994

Prepared for the U.S. Department of Energy Office of Environmental Restoration and Waste Management

P.O. Box 1970

Richland, Washington 99352

Hanford Operations and Engineering Contractor for the

U.S. Department of Energy under Contract DE-AC06-87RL 10930

Copyriaht Lloense By moceptance of thie article, the pubisher and/or recipient ectenowledges the U.S. Government's right to Copyright Lloense By acceptance of thie articles the pubisher And/or recipient acknow 


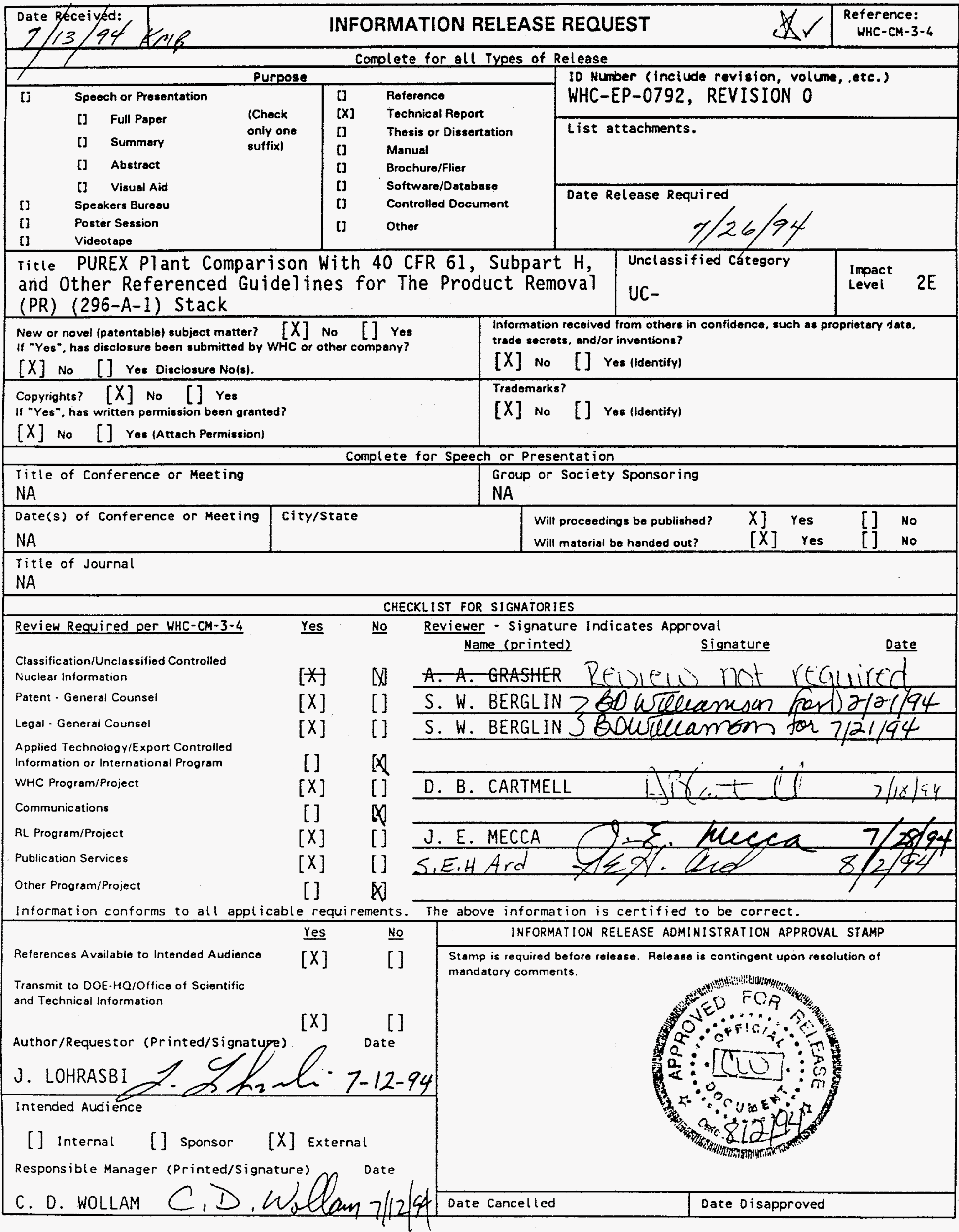




\section{DISCLAIMER}

This report was prepared as an account of work sponsored by an agency of the United States Government. Neither the United States Government nor any agency thereof, nor any of their employees, make any warranty, express or implied, or assumes any legal liability or responsibility for the accuracy, completeness, or usefulness of any information, apparatus, product, or process disclosed, or represents that its use would not infringe privately owned rights. Reference herein to any specific commercial product, process, or service by trade name, trademark, manufacturer, or otherwise does not necessarily constitute or imply its endorsement, recommendation, or favoring by the United States Government or any agency thereof. The views and opinions of authors expressed herein do not necessarily state or reflect those of the United States Government or any agency thereof. 


\section{DISCLAIMER}

Portions of this document may be illegible in electronic image products. Images are produced from the best available original document. 


\section{CONTENTS}

40 CFR 61, SUBPART H, NATIONAL EMISSION STANDARDS FOR EMISSIONS OF RADIONUCLIDES OTHER THAN RADON FROM U.S. DEPARTMENT OF ENERGY FACILITIES $\ldots \ldots \ldots \ldots \ldots \ldots \ldots \ldots \ldots \ldots$

40 CFR 60, APPENDIX A, REFERENCE METHOD 2, DETERMINATION OF STACK GAS VELOCITY AND VOLUMETRIC FLOW RATE (TYPE S PITOT TUBE) $\ldots \ldots \ldots \ldots \ldots \ldots \ldots \ldots \ldots$

40 CFR 60, APPENDIX A, REFERENCE METHOD 1, SAMPLE AND VELOCITY TRAVERSES FOR STATIONARY SOURCES $\ldots \ldots \ldots \ldots \ldots$

ANSI N13.1-1969, GUIDE TO SAMPLING AIRBORNE RADIOACTIVE MATERIALS IN NUCLEAR FACILITIES $4.2 .1 .2 \ldots \ldots \ldots \ldots \ldots \ldots \ldots$ METHOD 114 COMPARISON FOR STACK $296-A-1 \ldots \ldots \ldots \ldots$

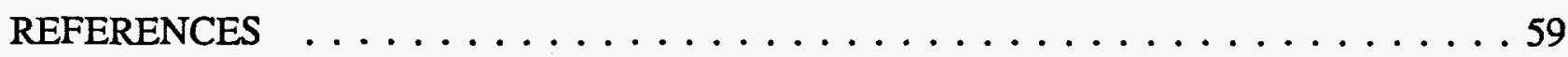


WHC-EP-0792

\section{LIST OF TABLES}

1 Calibration Procedures and Frequencies for the Record Sampler

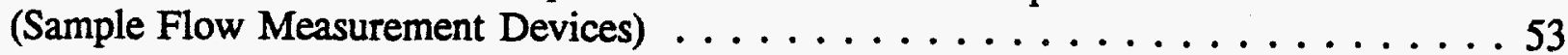

2 Calibration Procedures and Frequencies for Alpha Continuous Air Monitor Sampler (Sample Flow Measurement Devices) $\ldots \ldots \ldots \ldots 3$

3 Calibration Procedures and Frequencies for Stack Flow Measurement Devices . . . . . . . . . . . . . . . . . . . . 54 


\section{LIST OF TERMS}

$\begin{array}{ll}\text { AEA } & \text { Alpha Energy Analysis } \\ \text { ANSI } & \text { American National Standards Institute } \\ \text { ASTM } & \text { American Society For Testing And Materials } \\ \text { CAM } & \text { Continuous Air Monitor } \\ \text { CAP-88 } & \text { The Clean Air Act Assessment Package-1988 } \\ \text { CBRS } & \text { Computer Based Recall System } \\ \text { CFR } & \text { Code Of Federal Regulations } \\ \text { CY } & \text { Calendar Year } \\ \text { DOE } & \text { U.S. Department of Energy } \\ \text { EDE } & \text { Effective Dose Equivalent } \\ \text { EPA } & \text { U.S. Environmental Protection Agency } \\ \text { HP } & \text { Health Physics } \\ \text { LICCS } & \text { Laboratory Instrument Calibration Control System } \\ \text { MCA } & \text { Multichannel Analyzer } \\ \text { MEI } & \text { Maximally Exposed Individual } \\ \text { NIST } & \text { National Institute Of Standards And Technology } \\ \text { PNL } & \text { Pacific Northwest Laboratory } \\ \text { PR } & \text { Product Removal } \\ \text { PUREX } & \text { Plutonium-Uranium Extraction (Plant) } \\ \text { RL } & \text { U.S. Department Of Energy, Richland Field Office } \\ \text { WHC } & \text { Westinghouse Hanford Company } \\ \text { X/Q } & \text { Atmospheric Dispersion Factor }\end{array}$


WHC-EP-0792

This page intentionally left blank. 


\title{
PUREX PLANT COMPARISON WITH 40 CFR 61, SUBPART H, AND OTHER REFERENCED GUIDELINES FOR THE PRODUCT REMOVAL (PR) (296-A-1) STACK
}

\author{
40 CFR 61, SUBPART H, NATIONAL EMISSION STANDARDS FOR \\ EMISSIONS OF RADIONUCLIDES OTHER THAN RADON \\ FROM U.S. DEPARTMENT OF ENERGY FACILITIES
}

61.92 Standard Emissions of radionuclides to the ambient air from Department of Energy facilities shall not exceed those amounts that would cause any member of the public to receive in any year an effective dose equivalent of 10 mrem/yr.

Dose calculations for atmospheric radionuclide releases from the Hanford Site for calendar year (CY) 1992 were performed by Pacific Northwest Laboratory (PNL) using the approved U.S. Environmental Protection Agency (EPA) CAP-88 computer model. Emissions from discharge points in the Hanford Site 100, 200, 300, 400, and 600 areas were calculated based on results of analyses of continuous and periodic sampling conducted at the discharge points. These calculated emissions were provided for inclusion in the CAP-88 model by area and by individual facility for those facilities having the potential to contribute more than 10 percent of the Hanford Site total or to result in an impact of greater than 0.1 mrem per year to the maximally exposed individual (MEI). Also included in the assessment of offsite dose modeling are the measured radioactive emissions from all Hanford Site stacks that have routine monitoring performed. Record sampling systems have been installed on all stacks and vents that use exhaust fans to discharge air that potentially may carry airborne radioactivity. Estimation of activity from ingrowth of long-lived radioactive progeny is not included in the CAP-88 model; therefore, the Hanford Site GENII code (Napier et al. 1988) was used to supplement the CAP-88 dose calculations. When the dose to the MEI located in the Ringold area was calculated, the effective dose equivalent (EDE) from combined Hanford Site radioactive airborne emissions was shown to be 3.7E-03 mrem. This value was reported in the annual air emissions report prepared for the Hanford Site (RL 1993).

\subsection{Emission monitoring and test procedures}

(a) To determine compliance with the standard, radionuclide emissions shall be determined and effective dose equivalent values to members of the public calculated using EPA approved sampling procedures, computer models CAP-88 or AIRDOS-PC, or other procedures for which EPA has granted prior approval.

Dose calculations for atmospheric radionuclide releases from the Hanford Site for CY 1992 were performed by PNL using the approved EPA Clean Air Act Assessment Package (CAP-88) computer model. Emissions from discharge points in the Hanford Site 100,200,300,400, and 600 areas were calculated based on results of analyses of continuous and periodic sampling conducted at the discharge points. These calculated emissions were provided for inclusion in the CAP- 88 model by area and by individual 
facility for those facilities having the potential to contribute more than 10 percent of the Hanford Site total or to result in an impact of greater than 0.1 mrem per year to the MEI. Estimation of activity from ingrowth of long-lived radioactive progeny is not included in the CAP-88 model; therefore, the Hanford Site GENII code (Napier et al. 1988) was used to supplement the CAP-88 dose calculations. When the dose to the maximally exposed individual located in the Ringold area was calculated, the EDE from combined Hanford Site radioactive airborne emissions was shown to be 3.7E-03 mrem. This value was reported in the annual air emissions report prepared for the Hanford Site (RL 1993).

(b) Radionuclide emission rates from point sources (atacks or vents) shall be measured in accordance with the following requirements or other procedures for which EPA has granted prior approval:

(1) Effluent flow rate measurements shall be made using the following methods:

(i) Reference Method 2 of Appendix A to part 60 shall be used to determine velocity and volumetric flow rates for stacks and large vents.

Documentation: Drawing H-2-75570 (WHC 1991)

Response: Based on the drawing referenced above, the velocity measuring location used by Hanford Site Vent and Balance personnel has a cross-sectional area sufficient to be considered a large stack; therefore, Reference Method 2 applies.

(ii) Reference Method 2A of Appendix A to part 60 shall be used to measure flow rates through pipes and small vents.

(iii) The frequency of the flow rate measurements shall depend upon the variability of the effluent flow rate. For variable flow rates, continuous or frequent flow rate measurements shall be made. For relatively constant flow rates only periodic measurements are necessary.

Although the stack flow rate is relatively constant, Reference Method 2 is not used. Instead, the flow is measured continuously, as described in Section 4.3.7 of Method 114.

(2) Radionuclides shall be directly monitored or extracted, collected and measured using the following methods:

(i) Reference Method 1 of Appendix A part 60 shall be used to select monitoring or sampling sites.

See point by point comparison with Method 1, Section 2.1 .

(ii) The effluent stream shall be directly monitored continuously with an in-line detector or representative samples of the effluent stream shall be withdrawn continuously from the sampling site following the guidance of ANSI N13.1-1969 (including Appendix A of ANSI N13.1). 
See point by point comparison with American National Standards Institute (ANSI) Standard N13.1-1969 (ANSI 1969).

(iii) Radionuclides shall be collected and measured using procedures based on the principles of measurement described in Appendix B, Method 114 [of part 61]. Use of methods based on principles of measurement different from those described in Appendix B, Method 114 must have prior approval from the Administrator. EPA reserves right to approve measurement procedures.

See point by point comparison with Method 114 .

(iv) A quality assurance program shall be conducted that meets the performance requirements described in Appendix B, Method 114.

See point by point comparison with Method 114.

(3) When it is impractical to measure the effluent flow rate as in (b)(1) or to monitor or sample an effluent stream as in (b)(2), see this section for further requirements.

(4) (i) Radionuclide emission measurements in conformance with the requirements of paragraph (b) of this section shall be made at all release points which have a potential to discharge radionuclides into the air in quantities which could cause an effective dose equivalent (EDE) in excess of $1 \%$ of the standard. All radionuclides which could contribute $>10 \%$ of the EDE for a release point shall be measured. For other release points with potential to release radionuclides into the air, periodic confirmatory measurements shall be made to verify the low emissions.

WHC-SD-CP-TI-188 indicates that this stack should be measured (WHC 1994a).

(ii) In evaluating the potential of a release point to discharge radionuclides into the air, for the purpose of this section, the estimated RAD release rates shall be based on the discharge of the effluent stream that would result if all pollution control equipment did not exist, but the facility operations were otherwise normal.

Offsite dose calculations were performed on all stacks (registered with the Washington Department of Health under Permit FF-01) without pollution control equipment and using the PNL unit dose conversions. A total of 15 Hanford Site stacks exceeded the 0.1-mrem criterion and will require continuous monitoring in accordance with provisions of 40 CFR 61.93(b).

(5) Environmental measurements of radionuclide air concentrations at critical receptor locations may be used as an alternative to air dispersion calculations in demonstrating compliance with the standard if the owner or operator meets the following criteria:

(i) The air at point of measurement shall be continuously sampled for collection of radionuclides.

(ii) Major contributing radionuclides to the EDE must be collected and measured. 
(iii) Rad concentrations causing an EDE of $10 \%$ of the standard shall be readily detectable and distinguishable from background.

(iv) Net measured radionuclide concentrations shall be compared to the concentration levels in Table 2 of App. E [part 61] to determine compliance with the standard. In the case of multiple radionuclides, compliance is demonstrated if the value for all rad is less than the concentration levels in Table 2, and the sum of the fractions that result when each measured concentration value is divided by the value in Table 2 for each rad is $<1$.

(v) A program for quality assurance shall be conducted meeting the requirements of App. B, Method 114 [part 61].

(vi) Use of environmental measurements to demonstrate compliance with the standard if subject to prior approval of EPA.

This requirement is not applicable. Air dispersion calculations are performed.

\subsection{Compliance and reporting.}

(a) Compliance with this standard shall be determined by calculating the highest EDE to any member of the public at any offsite point where there is a residence, school, business, or office. Each facility shall submit an annual report to both EPA HQ and Regional by June 30, which includes monitoring results and dose calculations required by 61.43 (a) for the previous calendar year.

The Ringold location was chosen several years ago as the area where the offsite dose from all air pathways would be the highest for the MEI for the Hanford Site. The selection of Ringold was made because nearly all of the dose from air releases in recent years has been contributed by radionuclides from the Plutonium-Uranium Extraction (PUREX) Plant stack. The Ringold area is the closest farming area to the PUREX Plant, and it realistically matches the assumption that the MEI diet consists of 100 percent home-grown food. The Ringold area historically has been capable of producing all of the items in the MEI diet with the possible exception of cereal grain. The Ringold area lies the path of the prevailing winds from the 200 East Area. The atmospheric dispersion factor $(\mathrm{X} / \mathrm{Q})$ at Ringold is historically within 10 percent to 20 percent of the maximum offsite $X / Q$ value associated with the 200 Areas' releases. The maximum value usually occurs in an adjacent sector where there is no farming.

The U.S. Department of Energy Richland Field Office (RL), provided the annual report for CY 1992 (RL 1993) to the U.S. Department of Energy, Headquarters; the EPA, Region X, personnel; and the Washington Department of Health personnel in compliance with the regulatory deadline.

(b) In addition to the requirements of paragraph (a) of this section, an annual report shall include the following information: (Future annual reports will also address the following requirements.) 
(1) Name and location of facility.

Refer to RL-93-36, Pages 1-5 through 1-29. The Hanford Site summary is discussed on pages 1-1 through 1-5.

(2) List of radioactive materials used at the facility.

Refer to RL-93-36, Table 2-1 on pages 2-2 through 2-11. Please also refer to the explanatory remarks for 40 CFR 61.93(b)(4)(i) above.

(3) Description of handling and processing of rad materials at the facility.

Refer to RL-93-36, Pages 1-5 through 1-29.

(4) List of the stacks and vents (or other points where radioactive materials are released to the atmosphere.

Refer to RL-93-36, Pages 1-5 through 1-29.

(5) A description of the effluent controls that are used on each stack vent of release point, and an estimate of the efficiency of each control device.

Refer to RL-93-36, Table 2-1 on pages 2-2 through 2-11.

(6) Distances from the points of release to the nearest residence, school, business or office and the nearest farms producing vegetables, milk, and meat.

Refer to RL-93-36, Tables 3-2, 3-3, in Section 3. These tables show the CAP-88 dose estimates for the offsite individual at ringold exposed to radionuclide emissions from Hanford Site during 1992. Please also refer to the explanatory remarks for 40 CFR 61.94 above.

(7) The values used for all other input parameters for the computer models (meteorological data) and the source of these data.

Refer to RL-93-36. Input parameters are shown in Table 2-1, pages 2-2 through $2-11$. Annual average dispersion factors around the $100,200,300$, and 400 Areas during 1992 are given in Tables 3-5 through 3-9. These tables use site-specific measurements of the occurrence frequencies for wind speed, wind direction, and atmospheric stability. The products of the dispersion models are annual average dispersion factors (X/Q', in units of $\mathrm{Ci} / \mathrm{m}^{3}$ per $\mathrm{Ci} / \mathrm{s}$ or $\mathrm{s} / \mathrm{m}^{3}$ ) that, when combined with annual average release rates, will predict average radionuclide air concentrations for the year. 
(8) A brief description of all construction and modifications which were completed in the calendar year for which the report is prepared, but for which the requirement to apply for approval to construct or modify was waived under 61.96 .

\section{Refer to RL-93-36, Section 3.6.1. No projects were completed that needed approval for construction or waiver for modifications.}

(9) Each report shall be signed and dated by a corporate officer or public official in charge of the facility and containing a declaration of belief of accuracy and truth of the report.

Refer to RL-93-36, page 3-13, signed by John D. Wagoner, manager, RL.

(c) If the facility is not in compliance with the emission limits of 61.96 in the calendar year, reporting the information in (b) [above] must be done on a monthly basis starting immediately following the noncompliance annual report. Monthly reports shall also include:

Refer to RL-93-36. The annual emissions report indicates that the Hanford site is less than $10 \mathrm{mrem} / \mathrm{yr}$ for 1993.

(1) Controls or other changes installed to bring the facility into compliance.

(2) If the facility is under a judicial or administrative enforcement decree, the report will describe the facility performance under the terms of the decree.

(d) If this information is classified, it will be made available to EPA separately and handled in accordance with regulations.

This information is not classified; hence, this section is not applicable.

\subsection{Recordkeeping requirements.}

All facilities must maintain records documenting the source of input parameters including the results of all measurements, calculations, analytical methods, and procedure for determining EDE. Sufficient information to allow an independent auditor to verify the accuracy should be kept. The records must be kept at the site for at least five years and must be made available upon request to an authorized representative.

All records and data used in the generation and verification of regulatory reports are controlled in accordance with WHC-CM-4-2, QR 4.0, "Document Control," and QR 17.0, "Quality Assurance Records" (WHC 1992b).

\subsection{Applications to construct or modify.}

In addition to construction as defined under 40 CFR 61 , subpart A, any fabrication, erection or installation of a new building or structure within a facility that emits radionuclides is also defined as new construction for purposes of 40 CFR 61, subpart A.

(b) Application for approval [61.07] or notification of startup [61.09] does not need to be filed for any new construction or modification if the EDE caused by all emissions from the new construction or modification is less than $1 \%$ of the standard of 61.92. EDE shall be calculated using the source term derived from Appendix $\mathrm{D}$ as input to dispersion described in 61.93. A facility is eligible for this exemption only if it is in compliance based on its last annual report. 
(c) Conditions to approvals granted under 61.08 will not contain requirements for post approval reporting on operating conditions beyond those specified in 61.94 .

61.97 Exemption from the reporting and testine requirements of 40 CFR 61.10 .

All facilities designated under subpart $H$ are exempt from the reporting requirements of 40 CFR 61.10. 
WHC-EP-0792

This page intentionally left blank. 


\section{CFR 60, APPENDIX A, REFERENCE METHOD 2, DETERMINATION OF STACK GAS VELOCITY AND VOLUMETRIC FLOW RATE (TYPE S PITOT TUBE)}

Although the stack flow rate is relatively constant, Reference Method 2 is not used for demonstrating compliance. Instead, the flow is measured continuously, as described in Section 4.3.7 of Method 114.

Pitot traverses are performed as a check on the accuracy of the continuous flow instrumentation.

1.0 Principle and Applicability

1.1 Principle. The average gas velocity in a stack is determined from the gas density and from measurement of the average velocity head with a Type S (Stausscheibe or reverse type) pitot tube.

Documentation: 7-GN-56 (WHC 1993a)

Response: Average gas velocity is determined by averaging the results of exhaust duct traverses that have been conducted using a standard pitot tube and typically an Air Neotronics Limited MP Series 4 Autozero Digital Micromanometer (see description of this latter instrument in Section 2.2 below). Procedure 7-GN-56 indicates that traverse locations are determined in accordance with Section 9 of the American Industrial Hygiene Association Industrial Ventilation manual rather than EPA Method 1.

1.2 Applicability. This method is applicable for measurement of the average velocity of a gas stream and for quantifying gas flow.

This procedure is not applicable at measurement sites which fail to meet the criteria of Method 1 , Section 2.1. Also, the method cannot be used for direct measurement in cyclonic or swirling gas streams; Section 2.4 of Method 1 shows how to determine cyclonic or swirling flow conditions. When unacceptable conditions exist, alternative procedures, subject to the approval of the Administrator, U.S. Environmental Protection Agency, must be employed to make accurate flow rate determinations; examples of such alternative procedures are: (1) to install straightening vanes; (2) to calculate the total volumetric flow rate stoichiometrically; or (3) to move to another measurement site at which the flow is acceptable.

Response: At the traverse location used by Vent and Balance the stack diameter

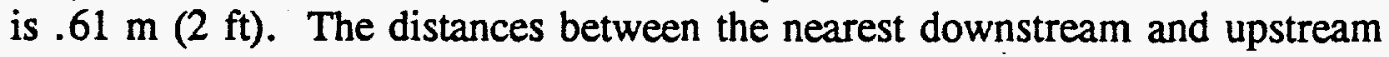
disturbances are $16.2 \mathrm{~m}$ and $2.7 \mathrm{~m}(53$ and $9 \mathrm{ft})$, respectively. The eight- and two-diameter criterion of Method 1, Section 2.1, is therefore met.

\section{$2.0 \quad$ Apparatus}

Specifications for the apparatus are given below. Any other apparatus that has been demonstrated (subject to approval of the Administrator) to be capable of meeting the specifications will be considered acceptable. 
2.1 Type S Pitot Tube. The Type S pitot tube (Figure 2-1) shall be made of metal tubing (e.g., stainless steel). It is recommended that the external tubing diameter (dimension Dt Figure 2-2b) be between 0.48 and 0.95 centimeter ( $3 / 16$ and $3 / 8 \mathrm{inch}$ ). There shall be an equal distance from the base of each leg of the pitot tube to its face-opening plane (dimensions PA and PB Figure 2-2b); it is recommended that this distance be between 1.05 and 1.50 times the external tubing diameter. The face openings of the pitot tube shall, preferably, be aligned as shown in Figure 2-2; however, slight misalignments of the openings are permissible (see Figure 2-3).

The Type $S$ pitot tube shall have a known coefficient, determined as outlined in Section 4 . An identification number shall be assigned to the pitot tube; this number shall be permanently marked or engraved on the body of the tube.

A standard pitot tube may be used instead of a Type $S$, provided that it meets the specifications of Sections 2.7 and 4.2: note, however, that the static and impact pressure holes of standard pitot tubes are susceptible to plugging in particulate-laden gas streams. Therefore, whenever a standard pitot tube is used to perform a traverse adequate proof must be furnished that the openings of the pitot tube have not plugged up during the traverse period; this can be done by taking a velocity head $\Delta \mathrm{P}$ reading at the final traverse point, cleaning out the impact and static holes of the standard pitot tube by "back-purging" with pressurized air, and then taking another $\Delta P$ reading. If the $\Delta P$ readings made before and after the air purge are the same ( \pm 5 percent), the traverse is acceptable. Otherwise, reject the run. Note that if $\triangle P$ at the final traverse point is unsuitably low, another point may be selected. If "back-purging" at regular intervals is part of the procedure, then comparative $\Delta \mathrm{P}$ readings shall be taken, as above, for the last two back purges at which suitably high $\Delta P$ readings are observed.

Documentation: 7-GN-56.

Response: The standard pitot tube is used in conjunction with a digital micromanometer to determine stack velocities. Document 7-GN-56 does not reference procedures used to prove that pitot tube openings have plugged during velocity measurements; however, because the measurement locations are positioned downstream from high-efficiency particulate air filter banks, it is unlikely that plugging of tube openings occurs. Note: As of April 1994, a new procedure is being used (PROC. NO. 1202) to include a pressure differential measurement after the last traverse (WHC 1994b).

2.2 Differential Pressure Gauge. An inclined manometer or equivalent device is used. Most sampling trains are equipped with a 10 -in. (water column) inclined-vertical manometer, having 0.01 -in. $\mathrm{H}_{2} \mathrm{O}$ divisions on the 0 - to 1 -in. inclined scale, and 0.1 -in. $\mathrm{H}_{2} \mathrm{O}$ divisions on the 1 - to 10 -in. vertical scale. This type of manometer (or other gauge of equivalent sensitivity) is satisfactory for the measurement of $\triangle P$ values as low as $1.3 \mathrm{~mm}\left(0.05 \mathrm{in}\right.$.) $\mathrm{H}_{2} \mathrm{O}$. However, a differential pressure gauge of greater sensitivity shall be used (subject to the approval of the Administrator), if any of the following is found to be true: (1) the arithmetic average of all $\Delta P$ readings at the traverse points in the stack is less than $1.3 \mathrm{~mm}\left(0.05 \mathrm{in}\right.$.) $\mathrm{H}_{2} \mathrm{O}$; (2) for traverses of 12 or more points, more than 10 percent of the individual $\Delta \mathrm{P}$ readings are below $1.3 \mathrm{~mm}\left(0.05 \mathrm{in}\right.$.) $\mathrm{H}_{2} \mathrm{O} ;$; (3) for traverses of fewer than 12 points, more than one $\Delta P$ reading is below $1.3 \mathrm{~mm}\left(0.05\right.$ in.) $\mathrm{H}_{2} \mathrm{O}$. Citation 18 in Section 6 describes commercially available instrumentation for the measurement of low-range gas velocities.

As an alternative to criteria (1) through (3) above, the following calculation may be performed to determine the necessity of using a more sensitive differential pressure gauge:

(see equation 40 CFR Pt. 60 App. A, Meth. 2, page 695) 
If $T$ is greater than 1.05, the velocity head data are unacceptable and a more sensitive differential pressure gauge must be used.

NOTE: If differential pressure gauges other than inclined manometers are used (e.g., magnehelic gauges) their calibration must be checked after each test series. To check the calibration of a differential pressure gauge, compare $\Delta P$ readings of the gauge with those of a gauge-oil manometer at a minimum of three points, approximately representing the range of $\Delta P$ values in the stack. If, at each point, the values of $\Delta P$ as read by the differential pressure gauge and gauge-oil manometer agree to within 5 percent, the differential pressure gauge shall be considered to be in proper calibration. Otherwise, the test series shall either be voided, or procedures to adjust the measured $\Delta P$ values and final results shall be used subject to the approval of the Administrator.

Documentation: 7-GN-56 and manufacturer's product literature.

Response: An Air Neotronics MP Series 4 Autozero Digital Micromanometer (Air Neotronics Limited) typically is used to determine differential pressure and flow velocity. This instrument consists of a differential capacitance transducer and internal electronics that allow the instrument to calculate and display corrected velocity readings directly from pitot tube probes. Dynamic pressure signals from pitot static and total head tubes are corrected automatically within the instrument and displayed in feet per minute. The instrument is capable of resolving pressure to $.025 \mathrm{~mm}\left(0.001 \mathrm{in}\right.$.) $\mathrm{H}_{2} \mathrm{O}$ (according to manufacturer's literature).

Procedure 7-GN-56 requires that the instrument carry a current calibration sticker, traceable to National Institute of Standards and Technology (NIST).

2.3 Temperature Gauge. A thermocouple, liquid-filled bulb thermometer, bimetallic thermometer, mercury-in-glass thermometer, or other gauge, capable of measuring temperature to within 1.5 percent of the minimum absolute stack temperature shall be used. The temperature gauge shall be attached to the pitot tube such that the sensor tip does not touch any metal; the gauge shall be in an interference-free arrangement with respect to the pitot tube face openings (see Figure 2-1 and also Figure 2-7 in Section 4). Alternate positions may be used if the pitot tube-temperature gauge system is calibrated according to the procedure of Section 4. Provided that a difference of not more than 1 percent in the average velocity measurement is introduced, the temperature gauge need not be attached to the pitot tube; this alternative is subject to the Approval of the Administrator.

\section{Documentation: $7-\mathrm{GN}-56$.}

Response: Temperatures are not measured. The density program internal to the micromanometer described above is used to compensate for temperature. Depending on process conditions, the correction to reported velocity values derived from the actual measurement of stack gas temperatures may be minimal.

2.4 Pressure Probe and Gauge. A piezometer tube and mercury-or water-filled U-tube manometer capable of measuring stack pressure to within $2.5 \mathrm{~mm}(0.1 \mathrm{in}$.) $\mathrm{Hg}$ is used. The static tap of a standard type pitot tube or one leg of a Type $S$ pitot tube with the face opening planes positioned parallel to the gas flow may also be used as the pressure probe. 
Documentation: 7-GN-56.

Response: The static tap of a standard pitot tube is used to measure stack pressure.

2.5 Barometer. A mercury, aneroid, or other barometer capable of measuring atmospheric pressure to within $2.5 \mathrm{~mm} \mathrm{Hg}(0.1 \mathrm{in} . \mathrm{Hg})$ may be used. In many cases, the barometric reading may be obtained from a nearby National Weather Service station, in which case the station value (which is the absolute barometric pressure) shall be requested and an adjustment for elevation differences between the weather station and the sampling point shall be applied at a rate of minus $2.5 \mathrm{~mm}(0.1 \mathrm{in}$.) $\mathrm{Hg}$ per 30 -meter (100 foot) elevation increase or vice-versa for elevation decrease.

\section{Documentation: 7-GN-56.}

Response: Barometric pressures are not measured. The density program internal to the micromanometer is set for standard conditions $\left[21^{\circ} \mathrm{C}\left(70^{\circ} \mathrm{F}\right)\right]$ and 76.00 $\mathrm{cm}$ (29.92 in.) mercury]. This introduces minimal error provided the temperature of the air stream varies no more than $-1.1^{\circ} \mathrm{C}\left(30^{\circ} \mathrm{F}\right)$ from standard air, the altitude of the site does not exceed $300 \mathrm{~m}(1,000 \mathrm{ft})$ above sea level, or the moisture content of the air is $.009 \mathrm{~kg} / \mathrm{kg}(0.02 \mathrm{lb} / \mathrm{lb})$ of dry air or less.

2.6 Gas Density Determination Equipment. Method 3 equipment, if needed (see Section 3.6), to determine the stack gas dry molecular weight, and Reference Method 4 or Method 5 equipment for moisture content determination; other methods may be used subject to approval of the Administrator.

Documentation: 7-GN-56.

Response: Stack gas moisture content is not determined. Considering the dry climate and conditioning of supply air, however, the correction to reported velocity values derived from the actual measurement of both stack dry molecular weight and moisture content would be minimal. The PUREX Plant is presently in the process of transition to shutdown and few activities are expected to add moisture to air exhausted through this stack.

2.7 Calibration Pitot Tube. When calibration of the Type S pitot tube is necessary (see Section 4), a standard pitot tube is used as a reference. The standard pitot tube shall, preferably, have a known coefficient, obtained either (1) directly from the National Bureau of Standards, Route 270, Quince Orchard Road, Gaithersburg, Maryland, or (2) by calibration against another standard pitot tube with an NBS-traceable coefficient. Alternatively, a standard pitot rube designed according to the criteria given in 2.7.1 through 2.7.5 below and illustrated in Figure 2-4 (see also Citations 7, 8, and 17 in Section 6) may be used. Pitot tubes designed according to these specifications will have baseline coefficients of about $0.99 \pm 0.01$.

Documentation: $7-\mathrm{GN}-56$.

Response: This requirement is not applicable, because the Type $S$ pitot tube is not used to measure velocity. 
2.7.1 Hemispherical (shown in Figure 2-4), ellipsoidal, or conical tip.

Documentation: Manufacturer's print 72-000031-00

(F. W. Dwyer Manufacturing Company).

Response: The standard pitot tubes used are procured commercially from sources such as F. W. Dwyer Manufacturing Company. They are constructed to standards outlined in Section 2.7 and contain hemispherical tips.

2.7.2 A minimum of six diameters straight run (based upon $D$, the external diameter of the tube) between the tip and the static pressure holes.

Documentation: Manufacturer's print 72-000031-00 (F. W. Dwyer Manufacturing Company).

Response: A minimum of six diameters straight run between tip and static pressure holes is provided.

2.7.3 A minimum of eight diameters straight run between the static pressure holes and the centerline of the external tube, following the 90 degree bend.

Documentation: Manufacturer's print 72-000031-00 (F. W. Dwyer Manufacturing Company).

Response: A minimum of eight diameters straight run between the static pressure holes and the centerline of the external tube is provided.

2.7.4 Static pressure holes of equal size (approximately $0.1 \mathrm{D}$ ), equally spaced in a piezometer ring configuration.

Documentation: Manufacturer's print 72-000031-00 (F. W. Dwyer Manufacturing Company).

Response: The above criteria are met by the manufacturer.

2.7.5 Ninety degree bend, with curved or mitered junction.

Documentation: Manufacturer's print 72-000031-00 (F. W. Dwyer Manufacturing Company).

Response: The above criteria are met by the manufacturer.

2.8 Differential Pressure Gauge for Type S Pitot Tube Calibration. An inclined manometer or equivalent is used. If the single-velocity calibration technique is employed (see Section 4.1.2.3), the calibration differential pressure gauge shall be readable to the nearest $0.13 \mathrm{~mm} \mathrm{H}_{2} \mathrm{O}\left(0.005 \mathrm{in}\right.$. $\left.\mathrm{H}_{2} \mathrm{O}\right)$. For 
multivelocity calibration, the gauge shall be readable to the nearest $0.13 \mathrm{~mm} \mathrm{H}_{2} \mathrm{O}\left(0.005\right.$ in. $\left.\mathrm{H}_{2} \mathrm{O}\right)$ for $\triangle P$ values between 1.3 and $25 \mathrm{~mm} \mathrm{H}_{2} \mathrm{O}\left(0.05\right.$ and 1.0 in. $\left.\mathrm{H}_{2} 0\right)$, and to the nearest $1.3 \mathrm{~mm} \mathrm{H}_{2} \mathrm{O}(0.05$ in. $\left.\mathrm{H}_{2} \mathrm{O}\right)$ for $\triangle \mathrm{P}$ values above $25 \mathrm{~mm} \mathrm{H}_{2} \mathrm{O}\left(1.0 \mathrm{in}\right.$. $\left.\mathrm{H}_{2} \mathrm{O}\right)$. A special, more sensitive gauge will be required to read $\triangle P$ values below $1.3 \mathrm{~mm} \mathrm{H}_{2} \mathrm{O}\left[0.05\right.$ in. $\left.\mathrm{H}_{2} \mathrm{O}\right]$ (see Citation 18 in Section 6).

Documentation: 7-GN-56.

Response: This requirement is not applicable. The Type $S$ pitot tube is not used.

\subsection{Procedure}

Procedures described in these sections shall be used to determine the stack velocity when the Type S pitot tube is used.

Documentation: 7-GN-56.

Response: This requirement is not applicable. The Type S pitot tube is not used

3.1 Set up the apparatus as shown in Figure 2-1. Capillary tubing or surge tanks installed between the manometer and pitot tube may be used to dampen $\Delta P$ fluctuations. It is recommended, but not required, that a pretest leak-check be conducted, as follows: (1) blow through the pitot impact opening until at least $7.6 \mathrm{~cm} \mathrm{(3} \mathrm{in.)} \mathrm{H}_{2} \mathrm{O}$ velocity pressure registers on the manometer; then, close off the impact opening. The pressure shall remain stable for at least 15 seconds; (2) do the same for the static pressure side, except using suction to obtain the minimum of $7.6 \mathrm{~cm}(3 \mathrm{in}.) \mathrm{H}_{2} 0$. Other leak check procedures, subject to the approval of the Administrator, may be used.

3.2 Level and zero the manometer. Because the manometer level and zero may drift due to vibrations and temperature changes, make periodic checks during the traverse. Record all necessary data as shown in the example data sheet (Figure 2-5).

3.3 Measure the velocity head and temperature at the traverse points specified by Method 1 . Ensure that the proper differential pressure gauge is being used for the range of $\Delta \mathrm{P}$ values encountered (see Section 2.2). If it is necessary to change to a more sensitive gauge, do so, and remeasure the $\triangle P$ and temperature readings at each traverse point. Conduct a post-test leak-check (mandatory), as described in Section 3.1 above, to validate the traverse run.

3.4 Measure the static pressure in the stack. One reading is usually adequate.

3.5 Determine the atmospheric pressure.

3.6 Determine the stack gas dry molecular weight. For combustion processes or processes that emit essentially $\mathrm{CO}_{2}, \mathrm{O}_{2}, \mathrm{CO}$ and $\mathrm{N}_{2}$, use Method 3. For processes emitting essentially air, an analysis need not be conducted; use a dry molecular weight of 29.0. For other processes, other methods, subject to the approval of the Administrator, must be used.

3.7 Obtain the moisture content from Reference Method 4 (or equivalent) or from Method 5.

3.8 Determine the cross-sectional area of the stack or duct at the sampling location. Whenever possible, physically measure the stack dimensions rather than using blueprints. 
4.0 Calibration

4.1 Type S Pitot Tube. Before its initial use, carefully examine the Type S pitot tube in top, side, and end views to verify that the face openings of the tube are aligned within the specifications illustrated in Figure 2-2 or 2-3. The pitot tube shall not be used if it fails to meet these alignment specifications.

After verifying the face opening alignment, measure and record the following dimensions of the pitot tube: (a) the external tubing diameter (dimension $D_{1}$, Figure 2-2b); and (b) the base-to-opening plane distances (dimensions $P_{A}$, and $P_{B}$, Figure 2-2b). If $D t$ is between 0.48 and $0.95 \mathrm{~cm}(3 / 16$ and $3 / 8$ in.) and if $P_{A}$, and $P_{B}$, are equal and between 1.05 and $1.50 D_{\text {, }}$, there are two possible options: (1) the pitot tube may be calibrated according to the procedure outlined in Sections 4.1.2 through 4.1.5 below, or (2) a baseline (isolated tube) coefficient value of 0.84 may be assigned to the pitot tube. Note, however, that if the pitot tube is part of an assembly, calibration may still be required, despite knowledge of the baseline coefficient value (see Section 4.1.1).

If $D_{l}, P_{A}$, and $P_{B}$ are outside the specified limits, the pitot tube must be calibrated as outlined in 4.1.2 through 4.1 .5 below.

\section{Documentation: 7-GN-56.}

\section{Response: This requirement is not applicable.}

4.1.1 Type S Pitot Tube Assemblies. During sample and velocity traverses, the isolated Type S pitot tube is not always used; in many instances, the pitot tube is used in combination with other source-sampling components (thermocouple, sampling probe, nozzle) as part of an "assembly." The presence of other sampling components can sometimes affect the baseline value of the Type $S$ pitot tube coefficient (Citation 9 in Section 6); therefore an assigned (or otherwise known) baseline coefficient value may or may not be valid for a given assembly. The baseline and assembly coefficient values will be identical only when the relative placement of the components in the assembly is such that aerodynamic interference effects are eliminated. Figures 2-6 through 2-8 illustrate interference-free component arrangements for Type S pitot tubes having external tubing diameters between 0.48 and $0.95 \mathrm{~cm}(3 / 16$ and $3 / 8 \mathrm{in}$.). Type $S$ pitot tube assemblies that fail to meet any or all of the specifications of Figures 2-6 through 2-8 shall be calibrated according to the procedure outlined in Sections 4.1.2 through 4.1.5 below, and prior to calibration, the values of the intercomponent spacings (pitot-nozzle, pitot-thermocouple, pitot-probe sheath) shall be measured and recorded.

NOTE: Do not use any Type $S$ pitot tube assembly which is constructed such that the impact pressure opening plane of the pitot tube is below the entry plane of the nozzle (see Figure 2-6b).

4.1.2 Calibration Setup. If the Type S Pitot tube is to be calibrated, one leg of the tube shall be permanently marked $A$, and the other, B. Calibration shall be done in a flow system having the following essential design features:

4.1.2.1 The flowing gas stream must be confined to a duct of definite cross-sectional area, either circular or rectangular. For circular cross-sections, the minimum duct diameter shall be $30.5 \mathrm{~cm}$ (12 in.); for rectangular cross-sections, the width (shorter side) shall be at least $25.4 \mathrm{~cm}$ (10 in.). 
4.1.2.2 The cross-sectional area of the calibration duct must be constant over a distance of 10 or more duct diameters. For a rectangular cross-section, use an equivalent diameter, calculated from the following equation, to determine the number of duct diameters:

$$
D_{e}=\frac{2 L W}{(L+W)}
$$

Where:

$D_{e}=$ Equivalent diameter

$L=$ Length

$\mathbf{W}=$ Width

To ensure the presence of stable, fully developed flow patterns at the calibration site, or "test section," the site must be located at least eight diameters downstream and two diameters upstream from the nearest disturbances.

NOTE: The eight- and two-diameter criteria are not absolute; other test section locations may be used (subject to approval of the Administrator), provided that the flow at the test site is stable and demonstrably parallel to the duct axis.

4.1.2.3 The flow system shall have the capacity to generate a test-section velocity around $915 \mathrm{~m} / \mathrm{min}(3,000 \mathrm{ft} / \mathrm{min})$. This velocity must be constant with time to guarantee steady flow during calibration. Note that Type $S$ pitot tube coefficients obtained by single-velocity calibration at $915 \mathrm{~m} / \mathrm{min}(3,000 \mathrm{ft} / \mathrm{min})$ will generally be valid to within \pm 3 percent for the measurement of velocities above $305 \mathrm{~m} / \mathrm{min}(1,000$ $\mathrm{t} / \mathrm{min}$ ) and to within \pm 5 to 6 percent for the measurement of velocities between 180 and $305 \mathrm{~m} / \mathrm{min}$ (600 and $1000 \mathrm{t} / \mathrm{min}$ ). If a more precise correlation between $\mathrm{Cp}$ and velocity is desired, the flow system shall have the capacity to generate at least four distinct time-invariant test-section velocities covering the velocity range from 180 and $1,525 \mathrm{~m} / \mathrm{min}(600$ to $5,000 \mathrm{ft} / \mathrm{min})$, and calibration data shall be taken at regular velocity intervals over this range (see Citations 9 and 14 in Section 6 for details).

4.1.2.4 Two entry ports, one each for the standard and Type $S$ pitot tubes, shall be cut in the test section; the standard pitot entry port shall be located slightly downstream of the Type $S$ port, so that the standard and Type $S$ impact openings will lie in the same cross-sectional plane during calibration. To facilitate alignment of the pitot tubes during calibration, it is advisable that the test section be constructed of plexiglass or some other transparent material.

4.1.3 Calibration Procedure. Note that this procedure is a general one and must not be used without first referring to the special considerations presented in Section 4.1.5. Note also that this procedure applies only to single-velocity calibration. To obtain calibration data for the $A$ and $B$ sides of the Type $S$ pitot tube, proceed as follows:

4.1.3.1 Make sure that the manometer is properly filled and that the oil is free from contamination and is of the proper density. Inspect and leak-check all pitot lines; repair or replace if necessary. 
4.1.3.2 Level and zero the manometer. Turn on the fan and allow the flow to stabilize. Seal the Type $S$ entry port.

4.1.3.3 Ensure that the manometer is level and zeroed. Position the standard pitot tube at the calibration point (determined as outlined in Section 4.1.5.1), and align the tube so that its tip is pointed directly into the flow. Particular care should be taken in aligning the tube to avoid yaw and pitch angles. Make sure that the entry port surrounding the tube is properly sealed.

4.1.3.4 Read $\Delta \mathbf{P}$ ad and record its value in a data table similar to the one shown in Figure 2-9. Remove the standard pitot tube from the duct and disconnect it from the manometer. Seal the standard entry port.

4.1.3.5 Connect the Type $S$ pitot tube to the manometer. Open the Type S entry port. Check the manometer level and zero. Insert and align the Type $S$ pitot tube so that its A side impact opening is at the same point as was the standard pitot tube and is pointed directly into the flow. Make sure that the entry port surrounding the tube is properly sealed.

4.1.3.6 Read $\Delta P$, and enter its value in the data table. Remove the Type $S$ pitot tube from the duct and disconnect it from the manometer.

4.1.3.7 Repeat steps 4.1.3.3 through 4.1.3.6 above until three pairs of $\Delta \mathbf{P}$ readings have been obtained.

4.1.3.8 Repeat steps 4.1.3.3 through 4.1.3.7 above for the B side of the Type $S$ pitot tube.

4.1.3.9 Perform calculations, as described in Section 4.1.4 below.

\subsubsection{Calculations.}

4.1.4.1 For each of the six pairs of $\triangle P$ readings (i.e., three from side $A$ and three from side B) obtained in Section 4.1.3 above, calculate the value of the Type $S$ pitot tube coefficient as follows:

$$
C_{p(s)}=C_{p(s d)} \sqrt{\frac{\Delta p_{s t d}}{\Delta p_{s}}}
$$

Where:

$C_{p(s)}=$ Type S Pitot tube coefficient

$C_{p(d)}=$ Standard Pitot tube coefficient: use 0.99 if the coefficient is unknown and the tube is designed according to the criteria of Sections 2.7 .1 to 2.7.5 of this method.

$\Delta \mathrm{P}_{\text {ud }}=$ Velocity head measured by the standard pitot tube, $\mathrm{cm} \mathrm{H}_{2} \mathrm{O}$ (in. $\mathrm{H}_{2} \mathrm{O}$ )

$\Delta P_{1}=$ Velocity head measured by the Type $S$ pitot tube, $\mathrm{cm} \mathrm{H}_{2} \mathrm{O}$ (in. $\mathrm{H}_{2} \mathrm{O}$ ) 
4.1.4.2 Calculate $C_{p}$ (side $A$ ), the mean $A$ side coefficient, and $C_{p}$ (side $B$ ), the mean $B$ side coefficient: calculate the difference between these two average values.

4.1.4.3 Calculate the deviation of each of the three $A$-side values of $C_{p}(s)$ from $C_{p}$ (side $A$ ), and the deviation of each $B$-side value of $C_{p}(s)$ from $C_{p}$ (side $B$ ). Use the following equation:

$$
\text { Deviation }=C_{p(s)}-\overline{C_{p}}(A \text { or } B)
$$

4.1.4.4 Calculate $\alpha$, the average deviation from the mean, for both the $A$ and $B$ sides of the pitot tube. Use the following equation:

$$
\alpha(\text { side } A \text { or } B)=\frac{\sum_{1}^{3} \mid C_{p(s)}-\overline{C_{p}}(A \text { or } B) \mid}{3}
$$

4.1.4.5 Use the Type $S$ pitot tube only if the values of $\alpha$ (side A) and $\alpha$ (side B) are less than or equal to 0.01 and if the absolute value of the difference between $C_{p}(A)$ and $C_{p}(B)$ is 0.01 or less.

\subsubsection{Special considerations.}

\subsubsection{Selection of calibration point.}

4.1.5.1.1 When an isolated Type $S$ pitot tube is calibrated, select a calibration point at or near the center of the duct, and follow the procedures outlined in Section 4.1.3 and 4.1.4 above. The Type $S$ pitot coefficients so obtained, i.e., $C_{p}$ (side $A$ ) and $C_{p}$, (side $B$ ), will be valid, so long as either: (1) the isolated pitot tube is used; or (2) the pitot tube is used with other components (nozzle, thermocouple, sample probe) in an arrangement that is free from aerodynamic interference effects (see Figures 2-6 through 2-8).

4.1.5.1.2 For Type $S$ pitot tube-thermocouple combinations (without sample probe), select a calibration point at or near the center of the duct, and follow the procedures outlined in Sections 4.1.3 and 4.1.4 above. The coefficients so obtained will be valid so long as the pitot tube-thermocouple combination is used by itself or with other components in an interference-free arrangement (Figures 2-6 and 2-8).

4.1.5.1.3 For assemblies with sample probes, the calibration point should be located at or near the center of the duct; however, insertion of a probe sheath into a small duct may cause significant cross-sectional area blockage and yield incorrect coefficient values (Citation 9 in Section 6). Therefore, to minimize the blockage effect, the calibration point may be a few inches off-center if necessary. The actual blockage effect will be 
negligible when the theoretical blockage, as determined by a projected-area model of the probe sheath, is 2 percent or less of the duct cross-sectional area for assemblies without external sheaths (Figure 2-10a), and 3 percent or less for assemblies with external sheaths (Figure 2-10b).

4.1.5.2 For those probe assemblies in which pitot tube-nozzle interference is a factor (i.e., those in which the pitot-nozzle separation distance fails to meet the specification illustrated in Figure 2-6a), the value of $C_{p}(s)$ depends upon the amount of free-space between the tube and nozzle, and therefore is a function of nozzle size. In these instances, separate calibrations shall be performed with each of the commonly used nozzle sizes in place. Note that the single-velocity calibration technique is acceptable for this purpose, even though the larger nozzle sizes $(>0.635 \mathrm{~cm}$ or $1 / 4$ in.) are not ordinarily used for isokinetic sampling at velocities around 915 $\mathrm{m} / \mathrm{min}(3,000 \mathrm{ft} / \mathrm{min})$, which is the calibration velocity; note also that it is not necessary to draw an isokinetic sample during calibration (see Citation 19 in Section 6).

4.1.5.3 For a probe assembly constructed such that its pitot tube is always used in the same orientation, only one side of the pitot tube need be calibrated (the side which will face the flow). The pitot tube must still meet the alignment specifications of Figures 2-2 or 2-3, however, and must have an average deviation $(\sigma)$ value of 0.01 or less (see Section 4.1.4.4).

\subsubsection{Field Use and Recalibration.}

\subsubsection{Field Use.}

4.1.6.1.1 When a Type $S$ pitot tube (isolated tube or assembly) is used in the field, the appropriate coefficient value (whether assigned or obtained by calibration) shall be used to perform velocity calculations. For calibrated Type $S$ pitot tubes, the $A$ side coefficient shall be used when the $A$ side of the tube faces the flow, and the $B$ side coefficient shall be used when the $B$ side faces the flow; alternatively, the arithmetic average of the $A$ and $B$ side coefficient values may be used, irrespective of which side faces the flow.

4.1.6.1.2 when a probe assembly is used to sample a small duct (12 to 36 in. in diameter), the probe sheath sometimes blocks a significant part of the duct cross-section, causing a reduction in the effective value of $C_{p}(s)$. Consult Citation 9 in Section 6 for details. Conventional pitot-sampling probe assemblies are not recommended for use in ducts having inside diameters smaller than 12 inches (Citation 16 in Section 6).

\subsubsection{Recalibration.}

4.1.6.2.1 Isolated Pitot tubes. After each field use, the pitot tube shall be carefully reexamined in top, side, and end views. If the pitot face openings are still aligned within the specifications illustrated in Figures $2-2$ or $2-3$, it can be assumed that the baseline coefficient of the pitot tube has not changed. If, however, the tube has been damaged to the extent that it no longer meets the specifications of Figures 2-2 or 2-3, 
the damage shall either be repaired to restore proper alignment of the face openings or the tube shall be discarded.

4.1.6.2.2 Pitot tube Assemblies. After each field use, check the face opening alignment of the pitot tube, as in Section 4.1.6.2.1; also, remeasure the intercomponent spacings of the assembly. If the intercomponent spacings have not changed and the face opening alignment is acceptable, it can be assumed that the coefficient of the assembly has not changed. If the face opening alignment is no longer within the specifications of Figures 2-2 or 2-3, either repair the damage or replace the pitot tube (calibrating the new assembly, if necessary). If the intercomponent spacings bave changed, restore the original spacings or recalibrate the assembly.

4.2 Standard pitot tube (if applicable). If a standard pitot tube is used for the velocity traverse, the tube shall be constructed according to the criteria of Section 2.7 and shall be assigned a baseline coefficient value of 0.99 . If the standard pitot tube is used as part of the assembly, the tube shall be in an interference-free arrangement (subject to the approval of the Administrator).

\section{Documentation: 7-GN-56 and manufacturer's product literature.}

Response: The standard pitot tube used for velocity traverses meets the criteria of Section 2.7. It is used in conjunction with a digital micromanometer. The tube coefficient (undetermined) is an integral part of the internal program used by the micromanometer to determine the pressure differential and flow velocity.

4.3 Temperature Gauges. After each field use, calibrate dial thermometers, liquid-filled bulb thermometers, thermocouple-potentiometer systems, and other gauges at a temperature within 10 percent of the average absolute stack temperature. For temperatures up to $405^{\circ} \mathrm{C}\left(761^{\circ} \mathrm{F}\right)$ use an ASTM mercury-in-glass reference thermometer, or equivalent, as a reference; alternatively, either a reference thermocouple and potentiometer (calibrated by NBS) or thermometric fixed points, e.g., ice bath and boiling water (corrected for barometric pressure) may be used. For temperatures above $405^{\circ} \mathrm{C}\left(761^{\circ} \mathrm{F}\right)$, use an NBS-calibrated reference thermocouple-potentiometer system or an alternate reference, subject to the approval of the Administrator.

If, during calibration, the absolute temperatures measured with the gauge being calibrated and the reference gauge agree within 1.5 percent, the temperature data taken in the field shall be considered valid. Otherwise, the pollutant emission test shall either be considered invalid or adjustments (if appropriate) of the test results shall be made, subject to the approval of the Administrator.

\section{Documentation: $7-\mathrm{GN}-56$.}

Response: No temperature-measuring devices are used.

4.4 Barometer. Calibrate the barometer used against a mercury barometer.

Documentation: 7-GN-56.

Response: No barometric-pressure-measuring devices are used. 


\subsection{Calculations}

Carry out calculations, retaining at least one extra decimal figure beyond that of the acquired data. Round off figures after final calculation.

5.1 Nomenclature. See 40 CFR Pt. 60 App. A, Meth. 2, page 707 and 708 for details).

Documentation: 7-GN-56 and manufacturer's product literature.

Response: The density program internal to the digital micromanometer is used to determine stack gas velocities, which are recorded on data sheets and averaged. The volumetric flow rate is determined from the average flow velocity and crosssectional area. 
This page intentionally left blank. 


\section{CFR 60, APPENDIX A, REFERENCE METHOD 1, SAMPLE AND VELOCITY TRAVERSES FOR STATIONARY SOURCES}

1.0 Principle and Applicability

1.1 Principle. To aid in the representative measurement of pollutant emissions and/or total volumetric flow rate from a stationary source, a measurement site where the effluent stream is flowing in a known direction is selected, and the cross-section of the stack is divided into a number of equal areas. A traverse point is then located within each of these equal areas.

1.2 Applicability. This method is applicable to flowing gas streams in ducts, stacks, and flues. The method cannot be used when: (1) flow is cyclonic or swirling (see Section 2.4); (2) a stack is smaller than about 0.30 meter (12 in.) in diameter, or $0.071 \mathrm{~m}^{2}$ (113 in. ${ }^{2}$ ) cross-sectional area; or (3) the measurement site is less than two stack or duct diameters downstream or less than a half diameter upstream from a flow disturbance.

The requirements of this method must be considered before construction of a new facility from which emissions will be measured; failure to do so may require subsequent alterations to the stack or deviation from the standard procedure. Cases involving variants are subject to approval by the Administrator, U.S. Environmental Protection Agency.

This method applies. See Section 2.1 below.

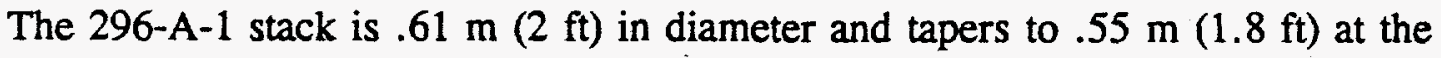
top.

The elevations of the sample ports are $10.4,11.6$, and $12.8 \mathrm{~m}(34,38$, and $42 \mathrm{ft})$ above the base, the location of the last major flow disturbance. The top of the stack is $22.6 \mathrm{~m}(74 \mathrm{ft})$ above the grade and $18.9 \mathrm{~m}(62 \mathrm{ft})$ above the base.

The sample ports are approximately 17,19 , and 21 diameters downstream the last major disturbance. The sample ports are approximately 14,12 , and 10 diameters upstream of the next major disturbance.

\subsection{Procedure}

2.1 Selection of Measurement Site. Sampling or velocity measurement is performed at a site located at least eight stack or duct diameters downstream and two diameters upstream from any flow disturbance such as a bend, expansion, or contraction in the stack, or from a visible flame. If necessary, an alternative location may be selected, at a position at least two stack or duct diameters downstream and a half diameter upstream from any flow disturbance. For a rectangular cross section, an equivalent diameter (D) shall be calculated from the following equation to determine the upstream and downstream distances:

$$
D_{0}=\frac{2 L W}{L+W}
$$


where $L=$ length and $W=$ width.

An alternative procedure is available for determining the acceptability of a measurement location not meeting the criteria above. This procedure, determination of gas flow angles at the sampling points and comparing the results with acceptability criteria, is described in Section 2.5.

The elevations of the sample ports are $10.4,11.6,12.8 \mathrm{~m}(34,38$, and $42 \mathrm{ft})$ above the base of the stack. The top of the stack is $18.9 \mathrm{~m}(62 \mathrm{ft})$ above the base.

The stack is $.61 \mathrm{~m}(2 \mathrm{ft})$ in diameter and tapers to $.55 \mathrm{~m}(1.8 \mathrm{ft})$ at the top.

The sample ports are approximately 17, 19, and 21 diameters downstream the last major disturbance. The sample ports are approximately 14, 12, and 10 diameters upstream of the next major disturbance.

\subsection{Determining the Number of Traverse Points.}

Not applicable: Method 1 is used for determining the sample site. The number of points is described in section A3.4, Comparison to ANSI N13.1-1969 (ANSI 1969).

2.2.1 Particulate traverses. When the eight- and two-diameter criterion can be met, the minimum number of traverse points shall be: (1) twelve, for circular or rectangular stacks with diameters (or equivalent diameters) greater than 0.61 meter $(24 \mathrm{in}$.); (2) eight, for circular stacks with diameters between 0.30 and 0.61 meter (12-24 in.); (3) nine, for rectangular stacks with equivalent diameters between 0.30 and 0.61 meter (12-24 in.).

Eight- and two-diameter criteria met. Samples are collected by a 4-port probe, not traverse. Sample port is described in comparison to ANSI N13.1-1969, Section A3.2 (ANSI 1969).

When the eight- and two-diameter criterion cannot be met, the minimum number of traverse points is determined from Figure 1-1. Before referring to the figure, however, determine the distances from the chosen measurement site to the nearest upstream and downstream disturbances, and divide each distance by the stack diameter or equivalent diameter, to determine the distance in terms of the number of duct diameters. Then, determine from Figure 1-1 the minimum number of traverse points that corresponds: (1) to the number of duct diameters upstream; and (2) to the number of diameters downstream. Select the higher of the two minimum numbers of traverse points, or a greater value, so that for circular stacks the number is a multiple of 4 , and for rectangular stacks, the number is one of those shown in Table 1-1.

Not applicable: eight and two criterion met. 
2.2.2 Velocity (Non-Particulate) Traverses. When velocity or volumetric flow rate is to be determined (but not particulate matter), the same procedure as that for particulate traverses (Section 2.2.1) is followed, except that Figure 1-2 may be used instead of Figure 1-1.

Not applicable. Velocity is measured by multipoint probe, not by traverse.

\section{NOTE: Velocity probe is discussed in Method 114 Comparison,} Section 4.3.7.

2.3 Cross-sectional Layout and Location of Traverse Points.

This requirement is not applicable. Method 1 is used for determining the sample site, not the number of points in a velocity traverse. Velocity is measured by multipoint probe, not by traverse.

2.3.1 Circular Stacks. Locate the traverse points on two perpendicular diameters according to Table 1-2 and the example shown on Figure 1-3. Any equation (for examples, see Citations 2 and 3 in the Bibliography) that gives the same values as those in Table 1-2 may be used in lieu of Table 1-2.

For particulate traverses, one of the diameters must be in a plane containing the greatest expected concentration variation, e.g., after bends, one diameter shall be in the plane of the bend. This requirement becomes less critical as the distance from the disturbance increases; therefore, other diameter locations may be used, subject to approval of the Administrator.

In addition for stacks having diameters greater than $0.61 \mathrm{~m} \mathrm{(24}$ in.) no traverse points shall be located within 2.5 centimeters (1.00 in.) of the stack walls; and for stack diameters equal to or less than $0.61 \mathrm{~m}(24 \mathrm{in}$.), no traverse points shall be located within $1.3 \mathrm{~cm}(0.50 \mathrm{in}$.) of the stack walls. To meet these criteria, observe the procedures given below.

This requirement is not applicable. Method 1 is used for determining the sample site. The number of points is described in section A3.4, Comparison to ANSI N13.1-1969 (ANSI 1969).

2.3.1.1 Stacks With Diameters Greater Than $0.61 \mathrm{~m}(24 \mathrm{in}$.). When any of the traverse points as located in Section 2.3 .1 fall within $2.5 \mathrm{~cm}(1.00 \mathrm{in}$.) of the stack walls, relocate them away from the stack walls to: (1) a distance of $2.5 \mathrm{~cm}(1.00 \mathrm{in}$.); or (2) a distance equal to the nozzle inside diameter, whichever is larger. These relocated traverse points (on each end of a diameter) shall be the "adjusted" traverse points.

Whenever two successive traverse points are combined to form a single adjusted traverse point, treat the adjusted point as two separate traverse points, both in the sampling (or velocity measurement) procedure, and in recording the data.

2.3.1.2 Stacks With Diameters Equal to or Less Than $0.61 \mathrm{~m}(24 \mathrm{in}$.). Follow the procedure in Section 2.3.1.1, noting only that any "adjusted" points should be relocated away from the stack walls to: (1) a distance of $1.3 \mathrm{~cm}(0.50 \mathrm{in}$.); or (2) a distance equal to the nozzle inside diameter, whichever is larger. 
This requirement is not applicable. Method 1 is used to determine the sample site. The number of points is described in Section A3.4, Comparison to ANSI N13.1-1969 (ANSI 1969).

2.3.2 Rectangular Stacks. Determine the number of traverse points as explained in Sections 2.1 and 2.2 of this method. From Table 1-1, determine the grid configuration. Divide the stack cross-section into as many equal rectangular elemental areas as traverse points, and then locate a traverse point at the centroid of each equal area according to the example in Figure 1-4.

If the tester desires to use more than the minimum number of traverse points, expand the "minimum number of traverse points" matrix (see Table 1-1) by adding the extra traverse points along one or the other or both legs of the matrix; the final matrix need not be balanced. For example, if a $4 \times 3$ "minimum number of points" matrix were expanded to 36 points, the final matrix could be $9 \times 4$ or $12 \times 3$, and would not necessarily have to be $6 \times 6$. After constructing the final matrix, divide the stack cross-section into as many equal rectangular, elemental areas as traverse points, and locate a traverse point at the centroid of each equal area.

The situation of traverse points being too close to the stack walls is not expected to arise with rectangular stacks. If this problem should ever arise, the Administrator must be contacted for resolution of the matter.

This requirement is not applicable because The stack is circular, not rectangular.

2.4 Verification of Absence of Cyclonic Flow. In most stationary sources, the direction of stack gas flow is essentially parallel to the stack walls. However, cyclonic flow may exist (1) after such devices as cyclones and inertial demisters following venturi scrubbers.

There are no cyclones, inertial demisters, or venturi scrubbers on this system.

(2) in stacks having tangential inlets or other duct configurations which tend to induce swirling; in these instances, the presence or absence of cyclonic flow at the sampling location must be determined. The following techniques are acceptable for this determination.

This stack does not have a tangential inlet or other duct configuration that tends to induce swirling.

Level and zero the manometer. Connect a Type $S$ pitot tube to the manometer. Position the Type $S$ pitot tube at each traverse point, in succession, so that the planes of the face openings of the pitot tube are perpendicular to the stack cross-sectional plane; when the Type $S$ pitot tube is in this position, it is at " $0^{\circ}$ reference." Note the differential pressure $(\Delta \mathrm{P})$ reading at each traverse point. If a null (zero) pitot reading is obtained at $0^{\circ}$ reference at a given traverse point, an acceptable flow condition exists at that point. If the pitot reading is not zero at $0^{\circ}$ reference, rotate the pitot tube (up to $\pm 90^{\circ}$ yaw angle), until a null reading is obtained. Carefully determine and record the value of the rotation angle $(\alpha)$ to the nearest degree. After the null technique has been applied at each traverse point, calculate the average of the absolute values of $\alpha$; assign $\alpha$ values of $0^{\circ}$ to those points for which no rotation was required, and include these in the overall average. If the average value of $\alpha$ is greater than $20^{\circ}$, the overall flow condition in the stack is unacceptable and alternative methodology, subject to the approval of the Administrator, must be used to perform accurate sample and velocity traverses. 
The alternative procedure described in Section 2.5 may be used to determine the rotation angles in lieu of the procedure described above.

This requirement is not applicable. Because there are no cyclones, inertial demisters, venturi scrubbers, tangential inlets, or other duct configuration that tend to induce swirling, there is no need to determine the presence or absence of cyclonic flow.

2.5 Alternative Measurement Site Selection Procedure. This alternative applies to sources where measurement locations are less than 2 equivalent stack or duct diameters downstream or less than 1/2 duet diameter upstream from a flow disturbance. The alternative should be limited to ducts larger than 24 in. in diameter where blockage and wall effects are minimal. A directional flow sensing probe is used to measure pitch and yaw angles of the gas flow at $\mathbf{4 0}$ or more traverse points; the resultant angle is calculated and compared with acceptable criteria for mean and standard deviation.

NOTE: Both the pitch and yaw angles are measured from a line passing through the traverse point and parallel to the stack axis. The pitch angle is the angle of the gas flow component in the plane that INCLUDES the traverse line and is parallel to the stack axis. The yaw angle is the angle of the gas flow component in the plane PERPENDICULAR to the traverse line at the traverse point and is measured from the line passing through the traverse point and parallel to the stack axis.

This requirement is not applicable. The selected site is greater than 2 diameters downstream and 1/2 diameter upstream from a flow disturbance.

\subsubsection{Apparatus.}

This requirement is not applicable. See 2.5 above.

2.5.1.1 Directional Probe. Any directional probe, such as United Sensor Type DA Three-Dimensional Directional Probe, capable of measuring both the pitch and yaw angles of gas flows is acceptable. (NOTE: Mention of trade name or specific products does not constitute endorsement by the U.S. Environmental Protection Agency.) Assign an identification number to the directional probe, and permanently mark or engrave the number on the body of the probe. The pressure holes or directional probes are susceptible to plugging when used in particulate-laden gas streams. Therefore, a system for cleaning the pressure holes by "backpurging" with pressurized air is required.

This requirement is not applicable. See 2.5 above.

2.5.1.2 Differential Pressure Gauges. Inclined manometers, U-tube manometers, or other differential pressure gauges (e.g., magnehelic gauges) that meet the specifications described in Method 2, section 2.2.

NOTE: If the differential pressure gauge produces both negative and positive readings, then both negative and positive pressure readings shall be calibrated at a minimum of three points as specified in Method 2, section 2.2.

This requirement is not applicable. See 2.5 above. 
2.5.2 Traverse Points. Use a minimum of 40 traverse points for circular ducts and 42 points for rectangular ducts for the gas flow angle determinations. Follow section 2.3 and Table 1-1 or 1-2 for the location and layout of the traverse points. If the measurement location is determined to be acceptable according to the criteria in this alternative procedure, use the same traverse point number and locations for sampling and velocity measurements.

This requirement is not applicable. See 2.5 above.

\subsubsection{Measurement Procedure.}

This requirement is not applicable. See 2.5 above.

2.5.3.1 prepare the directional probe and differential pressure gauges as recommended by the manufacturer. Capillary tubing or surge tanks may be used to dampen pressure fluctuations. It is recommended, but not required, that a pretest leak check be conducted. To perform a leak check, pressurize or use suction on the impact opening until a reading of at least $7.6 \mathrm{~cm}(3 \mathrm{in}.) \mathrm{H}_{2} \mathrm{O}$ registers on the differential pressure gauge, then plug the impact opening. The pressure of a leak-free system will remain stable for at least 15 seconds.

This requirement is not applicable. See 2.5 above.

2.5.3.2 Level and zero the manometers. Since the manometer level and zero may drift because of vibrations and temperature changes, periodically check the level and zero during the traverse.

This requirement is not applicable. See 2.5 above.

2.5.3.3 Position the probe at the appropriate locations in the gas stream, and rotate until zero deflection is indicated for the yaw angle pressure gauge. Determine and record the yaw angle. Record the pressure gauge readings for the pitch angle, and determine the pitch angle from the calibration curve. Repeat this procedure for each traverse point. Complete a "back-purge" of the pressure lines and the impact openings prior to measurements of each traverse point.

A post-test check as described in section 2.5.3.1 is required. If the criteria for a leak-free system are not met, repair the equipment, and repeat the flow angle measurements.

This requirement is not applicable. See 2.5 above.

2.5.4 Calculate the resultant angle at each traverse point, the average resultant angle, and the standard deviation using the following equations. Complete the calculation retaining at least one extra significant figure beyond that of the acquired data. Round the values after the final calculations.

This requirement is not applicable. See 2.5 above.

2.5.4.1 Calculate the resultant angle at each traverse point:

This requirement is not applicable. See 2.5 above. 
2.5.5 The measurement location is acceptable if $R \leq 20^{\circ}$ and $S_{d} \leq 10^{\circ}$.

This requirement is not applicable. See 2.5 above.

2.5.6 Calibration. Use a flow system as described in Sections 4.1.2.1 and 4.1.2.2 of Method 2. In addition, the flow system shall have the capacity to generate two test-section velocities: one between 365 and $730 \mathrm{~m} / \mathrm{min}$ (1200 and $2400 \mathrm{ft} / \mathrm{min}$ ) and one between 730 and $1100 \mathrm{~m} / \mathrm{min}$ (2400 and $3610 \mathrm{ft} / \mathrm{min}$ ).

This requirement is not applicable. See 2.5 above.

2.5.6.1 Cut two entry ports in the test section. The axes through the entry ports shall be perpendicular to each other and intersect in the centroid of the test section. The ports should be elongated slots parallel to the axis of the test section and of sufficient length to allow measurement of pitch angles while maintaining the pitot head position at the test-section centroid. To facilitate alignment of the directional probe during calibration, the test section should be constructed of plexiglass or some other transparent material. All calibration measurement should be made at the same point in the test section, preferably at the centroid of the test-section.

This requirement is not applicable. See 2.5 above.

2.5.6.2 To ensure that the gas flow is parallel to the central axis of the test section, follow the procedure in Section $\mathbf{2 . 4}$ for cyclonic flow determination to measure the gas flow angles at the centroid of the test section from two test ports located $90^{\circ}$ apart. The gas flow angle measured in each port must be $\pm 2^{\circ}$ of $0^{\circ}$. Straightening vanes should be installed, if necessary, to meet this criterion.

\section{This requirement is not applicable. See 2.5 above.}

2.5.6.3 Pitch Angle Calibration. Performs a calibration traverse according to the manufacturer's recommended protocol in $5^{\circ}$ increments for angles from $-60^{\circ}$ to $+60^{\circ}$ at one velocity in each of the two ranges specified above. Average the pressure ratio values obtained for each angle in the two flow ranges, and plot a calibration curve with the average values of the pressure ratio (or other suitable measurement factor as recommended by the manufacturer) versus the pitch angle. Draw a smooth line through the data points. Plot also the data values for each traverse point. Determine the differences between the measured data values and the angle from the calibration curve at the same pressure ratio. The difference at each comparison must be within $2^{\circ}$ for angles between $0^{\circ}$ and $40^{\circ}$ and within $3^{\circ}$ for angles between $40^{\circ}$ and $60^{\circ}$.

This requirement is not applicable. See 2.5 above. 
2.5.6.4 Yaw Angle Calibration. Mark the three-dimensional probe to allow the determination of the yaw position of the probe. This is usually a line extending the length of the probe and aligned with the impact opening. To determine the accuracy of measurements of the yaw angle, only the zero or null position need be calibrated as follows. Place the directional probe in the test section, and rotate the probe until the zero position is found. With a protractor or other angle measuring device, measure the angle indicated by the yaw angle indicator on the three-dimensional probe. This should be within $2^{\circ}$ of $0^{\circ}$. Repeat this measurement for any other points along the length of the pitot where yaw angle measurements could be read in order to account for variations in the pitot markings used to indicate pitot head positions.

This requirement is not applicable. See 2.5 above. 


\section{ANSI N13.1-1969, GUIDE TO SAMPLING AIRBORNE RADIOACTIVE MATERIALS IN NUCLEAR FACILITIES 4.2.1.2}

4.2.1.2 Sampling point should be a minimum of five diameters (or 5 times the major dimension for rectangular ducts) downstream from abrupt changes in flow direction or prominent transitions.

The elevations of the sample ports are $10.4,11.6$, and $12.8 \mathrm{~m}(34,38$, and $42 \mathrm{ft}$ ) above base, which corresponds to the last major flow disturbance in the stack.

The stack is $.61 \mathrm{~m}(2 \mathrm{ft})$ in diameter and tapers to $.55 \mathrm{~m}(1.8 \mathrm{ft})$ at the top.

The sample ports are therefore approximately 17,19 , and 21 diameters above the last major disturbance and they are in compliance.

\subsubsection{Samples should be representative with respect to physical and chemical composition of airstream.}

The sampling points for the record sampler are a minimum of 17 stack diameters downstream from the last contributor and are designed to be isokinetic within the compliance criteria (stack and sample flow rates are checked daily to ensure near isokinesis $\pm 10 \%$ ).

4.3.1 Sensitivity and accuracy of the analytical or counting method will determine the minimum volume of air which must be sampled to obtain the requisite accuracy and precision of results.

A vacuum pump for the record sampler withdraws an air sample at an average flow rate of $8.2 \mathrm{E} 04 \pm 1.1 \mathrm{E} 04 \mathrm{~cm}^{3}\left(2.9 \pm 0.4 \mathrm{ft}^{3}\right) / \mathrm{min}$.

4.3.2 If possible, the sample should be large enough to permit $1 / 10$ the permissible level to be determined with reliability.

Documentation: WHC-EP-0141-2 shows that the PUREX Plant releases are below $1 / 10$ of the permissible level (WHC 1990).

The frequency of the record air samples have been for a full 168-hour (7-day) week, to ensure adequate sample. As of June 1994, sample times were increased to two weeks to obtain more sample for a better laboratory analysis.

5.2.2 Airborne particulate matter should be evaluated and characterized at regular intervals and before any anticipated process change.

Particulate matter is sampled continuously with sample filters removed at the frequency discussed above. 
The particulate size distribution was measured for this stack and results were reported in activities for the environmental monitor's line-loss study for fiscal year 1992 (WHC 1993b).

\subsubsection{Appropriate filtration should be chosen for sampling.}

Particulates are collected on a sample filter made of Gelman Versapor $3000^{*}$. According to the manufacturer, this filter medium has an efficiency of 95.8 percent for $0.3 \mu \mathrm{m}$ particles.

5.2.2.1.7 Filter holders and support should be chosen for proper chemical compatibility, mechanical strength, sealing, and ease of operation in changing filters. Sample air movers should have the capability of delivering the necessary air flow against the resistance of the sampling system.

Proper location and choice of flow measurement device and flow rate control is important.

Aluminum sample holders have been used for the sampling system. The sample holders are easily screwed apart and have a sealing ring to ensure that all the gas flows through the filter.

The sample flow measurement and control systems ensure that the air mover provides adequate air flow through the sampler. These systems are located downstream of the sample collection media to prevent degradation of the sample.

5.3 Airborne radioactive gases or volatile materials should be sampled by an appropriate method if present.

The 296-A-1 stack does not exhaust measurable radioactive gases; therefore, this section is not applicable to this stack.

A1. Minimization of the length and bends of sample delivery lines will contribute to representative sampling.

The sample lines are constructed to minimize bends.

A2. Selection of sampling position along a stack.

The distance from the last upstream disturbance to the point of sample extraction should be a minimum of five and preferably ten or more duct diameters downstream. Sampling from a vertical run avoids stratification due to gravity settling. Sampling as far downstream as possible avoids most transient variation in airstream quality.

The elevations of the sample ports are 10.4, 11.6, and $12.8 \mathrm{~m}(34,38$, and $42 \mathrm{ft})$ above the base of the stack, which is the location of the last major disturbance.

"Gelman Versapor 3000 is a registered trademark of Gelman Sciences, Inc. 
The stack is $.61 \mathrm{~m}(2 \mathrm{ft})$ in diameter and tapers to $.55 \mathrm{~m}(1.8 \mathrm{ft})$ at the top.

The sample ports are therefore approximately 17,19 , and 21 diameters above the last major disturbance and they are in compliance.

A3.1 Velocity and flow distribution should be known for the sampling point, and particle and gaseous composition should be representative.

The Reynold's number of the stack is approximately 250,000 , which is solidly in the turbulent regime. Since there are no sources of cyclonic flow, the flow pattern can be described as well developed turbulent and it is in compliance.

A3.2 A multiple number of withdrawal points each representing approximately equal areas based on the duct or stack dimensions is desirable.

The sampling probes that have been used for the record sampler and the Alpha continuous air monitor (CAM) are designed identically, and each has four inlet ports that span the diameter of the stack with different cross sectional areas.

The ports are arranged to collect air from the approximate centers of equal annular areas. (For an annulus, the "center" is half way between the inner and outer radii of an annulus.)

A3.3 The velocity distribution across the duct or stack should be known in order to establish isokinetic flow and representative sample points.

The Reynold's number of the stack is approximately 250,000 , which is solidly in the turbulent regime. Since there are no sources of cyclonic flow, the flow pattern can be described as well developed turbulent.

Sample flow rate is adjusted to maintain isokinesis in sampling system, see Method 114 Comparison, Sections 4.3.6 and 4.3.7. It is in compliance.

A3.4 Sampling probe configuration is recommended by figures in this standard, with minimum radius bends and precisely tapered probe end edges.

The 296-A-1 samplers use multipoint probes, as described in Figure A5 of ANSI N13.1-1969. The sampling probes for the record sampler and the Alpha CAM are identically designed, and each has four inlet ports that are arranged over equal annular areas (see drawing H-2-75571, WHC 1991). Note: For information purposes related to this study only, the sampling ports have been numbered $1,2,3$, and 4 .

Figure A5 specifies a length as approximately five times the diameter and the radius of the bend as more than five times the diameter. At the inlet, each port is tapered to a knife edge with a 15-degree angle. The diameter of the first port located at the center of the stack, is $0.61 \mathrm{~cm}(0.242 \mathrm{in}$.$) , and its length and$ 
radius are both $4.76 \mathrm{~cm}(1.875 \mathrm{in}$.$) , for a ratio of approximately 7.7$. The diameter of the second port located $18.4 \mathrm{~cm}(7.25 \mathrm{in}$.) from the center of the stack, is $.68 \mathrm{~cm}(0.269 \mathrm{in}$.$) , and its length and radius are both 6.4 \mathrm{~cm}(2.5 \mathrm{in}$.$) ,$ for a ratio of approximately 9.3. The diameter of the third port located $23.97 \mathrm{~cm}(9.438 \mathrm{in}$.) from the center of the stack, is $.7 \mathrm{~cm}(0.277 \mathrm{in}$.$) , and its$ length and radius are both $5.7 \mathrm{~cm}$ (2.25 in.), for a ratio of approximately 8.1 . The diameter of the fourth port located $28.42 \mathrm{~cm}$ (11.188 in.) from the center of the stack, is $.76 \mathrm{~cm}(0.302$ in.), and its length and radius are both $8.3 \mathrm{~cm}$ (3.25 in.), for a ratio of approximately 10.8 . The corresponding ratios are in compliance.

B1. Sampling line length should be kept to a minimum length. An estimate of the fraction of particles deposited in sampling lines under various conditions should be made using the experimental data presented in this appendix.

Using the lowest sample probe location for the record sample minimizes sample line length.

The methodology of Appendix B does not include the estimation of resuspension. It is believed that resuspension occurs because there are no indications that the lines are plugging. Furthermore, the results from sampling line loss study of this stack indicates that more large particles exit long sample lines than enter them. This observation is consistent with the view that deposited particles resuspend after agglomerating on the wall of the sample line with overall estimates of particle line loss in the 25 to 35 percent range in specific size intervals (WHC 1993b).

Velocities must be kept high enough to avoid appreciable losses by Brownian diffusion.

The sample flow has a Reynold's number of approximately 8,000 and it is in compliance.

B5 Elbows in sampling lines should be avoided if at all possible. When required, the bend radius of the elbow should be as long as practical, and design flow rates through any line containing an elbow should be kept low. When possible, the sampler installation should allow for probe removal in order to evaluate the losses in the probe entry elbow and to permit cleaning.

There are no unnecessary bends. The bend (in the sample probe) meets the criteria of Appendix A. The bends in sample line consist of two large radius $45^{\circ}$ angles.

The only difficulty in removal of the probe is its height above the ground. 


\section{METHOD 114 COMPARISON FOR STACK 296-A-1}

\subsection{Purpose and Background}

This method provides the requirements for: (1) Stack monitoring and sample collection methods appropriate for radionuclides; (2) radiochemical methods which are used in determining the amounts of radionuclides collected by the stack sampling and; (3) quality assurance methods which are conducted in conjunction with these measurements. These methods are appropriate for emissions for stationary sources. A list of references is provided.

Many different types of facilities release radionuclides into air. These radionuclides differ in the chemical and physical forms, half-lives and type of radiation emitted. The appropriate combination of sample extraction, collection and analysis for an individual radionuclide is dependent upon many interrelated factors including the mixture of other radionuclides present. Because of this wide range of conditions, no single method for monitoring or sample collection and analysis of a radionuclide is applicable to all types of facilities. Therefore, a series of methods based on "principles of measurement" are described for monitoring and sample collection and analysis which are applicable to the measurement of radionuclides found in effluent streams at stationary sources. This approach provides the user with the flexibility to choose the most appropriate combination of monitoring and sample collection and analysis methods which are applicable to the effluent stream to be measured.

\subsection{Stack Monitoring and Sample Collection Methods}

Monitoring and sample collection methods are described based on "principles of monitoring and sample collection" which are applicable to the measurement of radionuclides from effluent streams at stationary sources. Radionuclides of most elements will be in the particulate form in these effluent streams and can be readily collected using a suitable filter media. Radionuclides of hydrogen, oxygen, carbon, nitrogen, the noble gases and in some circumstances iodine will be in the gaseous form. Radionuclides of these elements will require either the use of an in-line or off-line monitor to directly measure the radionuclides, or suitable sorbers, condensers or bubblers to collect the radionuclides.

2.1 Radionuclides as Particulates. The extracted effluent stream is passed through a filter media to remove the particulates. The filter must have a high efficiency for removal of sub-micron particles. The guidance in ANSI N13.1-1969 shall be followed in using filter media to collect particulates (incorporated by reference-see $\$ 61.18$ ).

Response: Particulates are collected on a sample filter made of Gelman Versapor 3000 . According to the manufacturer, this filter medium has an efficiency of 95.8 percent for $0.3 \mu \mathrm{m}$ particles.

2.2 Radionuclides as Gases.

Response: Based on process knowledge, the 296-A-1 stack does not exhaust radionuclide gases; therefore, this section is not applicable to this stack.

2.3 Definition of Terms

Response: No answer is required. 


\subsection{Radionuclide Analysis Methods}

A series of methods based on "principles of measurement" are described which are applicable to the analysis of radionuclides collected from airborne effluent streams at stationary sources. These methods are applicable only under the conditions stated and within the limitations described. Some methods specify that only a single radionuclide be present in the sample or the chemically separated sample. This condition should be interpreted to mean that no other radionuclides are present in quantities which would interfere with the measurement.

Also identified (Table 1) are methods for a selected list of radionuclides. The listed radionuclides are those which are most commonly used and which have the greatest potential for causing dose to members of the public. Use of methods based on principles of measurement other than those described in this section must be approved in advance of use by the Administrator. For radionuclides not listed in Table 1, any of the described methods may be used provided the user can demonstrate that the applicability conditions of the method have been met.

The type of method applicable to the analysis of a radionuclide is dependent upon the type of radiation emitted, i.e., alpha, beta or gamma. Therefore, the methods described below are grouped according to principles of measurements for the analysis of alpha, beta and gamma emitting radionuclides.

\subsection{Methods for Alpha Emitting Radionuclides}

\subsubsection{Method A-1, Radiochemistry-Alpha Spectrometry.}

Principle: The element of interest is separated from other elements, and from the sample matrix using radiochemical techniques. The procedure may involve precipitation, ion exchange, or solvent extraction. Carriers (elements chemically similar to the element of interest) may be used. The element is deposited on a planchet in a very thin film by electrodeposition or by coprecipitation on a very small amount of carrier, such as lanthanum fluoride. The deposited element is then counted with an alpha spectrometer. The activity of the nuclide of interest is measured by the number of alpha counts in the appropriate energy region. A correction for chemical yield and counting efficiency is made using a standardized radioactive nuclide (tracer) of the same element. If a radioactive tracer is not available for the element of interest, a predetermined chemical yield factor may be used.

Applicability: This method is applicable for determining the activity of any alpha-emitting radionuclide, regardless of what other radionuclides are present in the sample provided the chemical separation step produces a very thin sample and removes all other radionuclides which could interfere in the spectral region of interest. APHA-605(2), ASTM-D-3972(13).

Response: The 222-S Laboratory method involves dissolution (LA-549-112), chemical separation (LA-943-123) (WHC 1992a), electrodeposition (LA-542-101), followed by alpha spectrometry (LA-508-161) (WHC 1994c). It meets all the requirements of the EPA-suggested method. This is used for analyzing ${ }^{241} \mathrm{Am},{ }^{238} \mathrm{Pu}$, and ${ }^{239.240} \mathrm{Pu}$ in the air filter samples. The activities of these nuclides are determined by direct comparison with the recoveries of NIST traceable ${ }^{243} \mathrm{Am}$ and ${ }^{236} \mathrm{Pu}$ tracers.

\subsubsection{Method A-2, Radiochemistry-Alpha Counting.}

Principle: The element of interest is separated from other elements, and from the sample matrix using radiochemistry. The procedure may involve precipitation, ion exchange, or solvent extraction. Carriers (elements chemically similar to the element of interest) may be used. The element is deposited on a planchet in a thin film and counted with a alpha counter. A correction for chemical yield (if necessary) is made. The alpha count rate measures the total activity of all emitting radionuclides of the separated element. 
Applicability: This method is applicable for the measurement of any alpha-emitting radionuclide, provided no other alpha emitting radionuclide is present in the separated sample. It may also be applicable for determining compliance, when other radionuclides of the separated element are present, provided that the calculated emission rate is assigned to the radionuclide which could be present in the sample that has the highest dose conversion factor. IDO-12096(18).

Response: Because the tracer technique is used in the separation process, this method is not used for air filter analysis.

\subsubsection{Method A-3, Direct Alpha Spectrometry.}

Principle: The sample, collected on a suitable filter, is counted directly on an alpha spectrometer. The sample must be thin enough and collected on the surface of the filter so that any absorption of alpha particle energy in the sample or the filter, which would degrade the spectrum, is minimal.

Applicability: This method is applicable to simple mixtures of alpha emitting radionuclides and only when the amount of particulates collected on the filter paper are relatively small and the alpha spectra is adequately resolved. Resolutions should be $50 \mathrm{keV}$ (FWHM) or better, ASTM-D-3084(16).

Response: The 222-S Laboratory method follows procedure LO-150-133, then LA-508-110 for total alpha counts (WHC 1992a), and finally LA-508-161 for alpha spectrometry (WHC 1994c). It partially meets the requirements of the EPA method. This method is usually used for emergency air samples. The sample is counted on the alpha counter of known efficiency to obtain the total alpha counts. In the alpha energy analysis (AEA), the relative peak fractions of different alpha emitters identified in the sample are determined. The peak fractions are then used to correct the total alpha counts and thus determine the activities of individual alpha nuclides present in the sample.

\subsubsection{Method A-4, Direct Alpha Counting (Gross alpha determination).}

Principle: The sample, collected on a suitable filter, is counted with an alpha counter. The sample must be thin enough so that self-absorption is not significant and the filter must be of such a nature that the particles are retained on the surface.

Applicability: Gross alpha determination may be used to measure emissions of specific radionuclides only (1) when it is known that the sample contains only a single radionuclide, or the identity and isotopic ratio of the radionuclides in the sample are well known, and (2) measurements using either Method A-1, A-2 or A-5 have shown that this method provides a reasonably accurate measurement of the emission rate. Gross alpha measurements are applicable to unidentified mixtures of radionuclides only for the purposes and under the conditions described in section 3.7. APHA-601(3), ASTM-D-1943(10).

Response: The 222-S Laboratory method follows procedure LA-508-110 or LA-508-114 (WHC 1992a). It meets all of the requirements stated in Method A-4.

\subsubsection{Method A-5, Chemical Determination of Uranium.}

Uranium: Uranium may be measured chemically by either colorimetry or fluorometry. In both procedures, the sample is dissolved, the uranium is oxidized to the hexavalent form and extracted into a suitable solvent. Impurities are removed from the solvent layer. For colorimetry, dibenzoylmethane is added, and the uranium is measured by the absorbance in a colorimeter. For fluorometry, a portion of the solution is fused with a sodium 
fluoride-lithium fluoride flux and the uranium is determined by the ultraviolet activated fluorescence of the fused disk in a fluorometer.

Applicability: This method is applicable to the measurements of emission rates of uranium when the isotopic ratio of the uranium radionuclides is well known. ASTM-E318(15), ASTM-D-2907(14).

Response: Total uranium is determined by procedure LA-925-107 (WHC 1992a). The laser-induced kinetic phosphorescence analyzer is an improvement over the old fluorometric method for uranium determination. It is highly sensitive (lower detection level of 50 parts per trillion is quite possible) because the laser frequency is used specifically for excitation of uranium atoms. It is faster and produces quality numbers. Quality can also be monitored during analysis. It exceeds the requirements in Method A-5.

\subsubsection{Method A-6, Radon-222-Continuous Gas Monitor.}

Principle: Radon-222 is measured directly in a continuously extracted sample stream by passing the air stream through a calibrated scintillation cell. Prior to the scintillation cell, the air stream is treated to remove particulates and excess moisture. The alpha particles from radon-222 and its decay products strike a zinc sulfide coating on the inside of the scintillation cell producing light pulses. The light pulses are detected by a photomultiplier tube which generates electrical pulses. These pulses are processed by the system electronics and the read out is in $\mathrm{pCi} / 1$ of radon-222.

Applicability: This method is applicable to the measurement of radon-222 in effluent streams which do not contain significant quantities of radon-220. Users of this method should calibrate the monitor in a radon calibration chamber at least twice per year. The background of the monitor should also be checked periodically by operating the instrument in a low radon environment. EPA 520/1-89-009(24).

Response: This requirement is not applicable at the 222-S Laboratory; direct monitoring of ${ }^{222} \mathrm{Rn}$ is not performed at the 222-S Laboratory.

\subsubsection{Method A-7, Radon-222-Alpha Track Detectors}

Principle: Radon-222 is measured directly in the effluent stream using alpha track detectors (ATD). The alpha particles emitted by radon-222 and its decay products strike a small plastic strip and produce submicron damage tracks. The plastic strip is placed in a caustic solution that accentuates the damage tracks which are counted using a microscope or automatic counting system. The number of tracks per unit area is corrected to the radon concentration in air using a conversion factor derived from data generated in a radon calibration facility.

Applicability: Prior approval from EPA is required for use of this method. This method is only applicable to effluent streams which do not contain significant quantities of radon-220, unless special detectors are used to discriminate against radon 220 . This method may be used only when ATDs have been demonstrated to produce data comparable to data obtained with Method A-6. Such data should be submitted to EPA when requesting approval for the use of this method. EPA 520/1-89-009(24).

Response: This requirement is not applicable; direct monitoring of ${ }^{222} \mathrm{Rn}$ is not performed at the 222-S Laboratory.

\subsection{Methods for Gaseous Beta Emitting Radionuclides.}

3.2.1 Method B-1, Direct Counting in Flow-Through Ionization Chambers. 
Principle: An ionization chamber containing a specific volume of gas which flows at a given flow rate through the chamber is used. The sample (effluent stream sample) acts as the counting gas for the chamber. The activity of the radionuclide is determined from the current measured in the ionization chamber.

Applicability: This method is applicable for measuring the activity of a gaseous beta emitting radionuclide in an effluent stream that is suitable as a counting gas, when no other beta-emitting nuclides are present. DOE/EP-0096(17), NCRP-58(23).

\section{Response: This requirement is not applicable because this measurement is not performed.}

\subsubsection{Method B-2, Direct Counting With In-line or Off-line Beta Detectors.}

Principle: The beta detector is placed directly in the effluent stream (in-line) or an extracted sample of the effluent stream is passed through a chamber containing a beta detector (off-line). The activities of the radionuclides present in the effluent stream are determined from the beta count rate, and a knowledge of the radionuclides present and the relationship of the gross beta count rate and the specific radionuclide concentration.

Applicability: This method is applicable only to radionuclides with maximum beta particle energies greater then $0.2 \mathrm{MeV}$. This method may be used to measure emissions of specific radionuclides only when it is known that the sample contains only a single radionuclide or the identity and isotopic ratio of the radionuclides in the effluent stream are well known. Specific radionuclide analysis of periodic grab samples may be used to identify the types and quantities of radionuclides present and to establish the relationship between specific radionuclide analyses and gross beta count rates.

This method is applicable to unidentified mixtures of gaseous radionuclides only for the purposes and under the conditions described in section 3.7.

\section{Response: This requirement is not applicable because this activity is not performed.}

\subsection{Methods for Non-Gaseous Beta Emitting Radionuclides.}

\subsubsection{Method B-3, Radiochemistry-Beta Counting.}

Principle: The element of interest is separated from other elements, and from the sample matrix by radiochemistry. This may involve precipitation, distillation, ion exchange, or solvent extraction. Carriers (elements chemically similar to the element of interest) may be used. The element is deposited on a planchet, and counted with a beta counter. Corrections for chemical yield and decay (if necessary) are made. The beta count rate determines the total activity of all radionuclides of the separated element. This method may also involve the radiochemical separation and counting of a daughter element, after a suitable period of ingrowth, in which case it is specific for the parent nuclide.

Applicability: This method is applicable for measuring the activity of any beta-emitting radionuclide, with a maximum energy greater than $0.2 \mathrm{MeV}$, provided no other radionuclide is present in the separated sample. APHA-608(5).

Response: The method for determining ${ }^{89} \mathrm{Sr},{ }^{90} \mathrm{Sr} /{ }^{90} \mathrm{Y}$ in air filter samples is carried out using procedures LA-549-112 (dissolution) and LA-220-103 (for chemical separation), followed by procedure LA-508-111 (total beta counting) (WHC 1992a). The laboratory method meets the requirements stated above. 


\subsubsection{Method B-4, Direct Beta Counting (Gross beta determination).}

Principle: The sample, collected on a suitable filter, is counted with a beta counter. The sample must be thin enough so that self-absorption corrections can be made.

Applicability: Gross beta measurements are applicable only to radionuclides with maximum beta particle energies greater than $0.2 \mathrm{MeV}$. Gross beta measurements may be used to measure emissions of specific radionuclides only (1) when it is known that the sample contains only a single radionuclide, and (2) measurements made using Method B-3 show reasonable agreement with the gross beta measurement. Gross beta measurements are applicable to mixtures of radionuclides only for the purposes and under the conditions described in section 3.7. APHA-602(4), ASTM-D-1890(11).

Response: For gross beta determination, procedure LA-508-110 or LA-508-114 is followed (WHC 1992a). It satisfies the Method B-4 requirements.

\subsubsection{Method B-5, Liquid Scintillation Spectrometry.}

Principle: An aliquot of a collected sample or the result of some other chemical separation or processing technique is added to a liquid scintillation "cocktail" which is viewed by photomultiplier tubes in a liquid scintillation spectrometer. The spectrometer is adjusted to establish a channel or "window" for the pulse energy appropriate to the nuclide of interest. The activity of the nuclide of interest is measured by the counting rate in the appropriate energy channel. Corrections are made for chemical yield where separations are made.

Applicability: This method is applicable to any beta-mitting nuclide when no other radionuclide is present in the sample or the separated sample provided that it can be incorporated in the scintillation cocktail. This method is also applicable for samples which contain more than one radionuclide but only when the energies of the beta particles are sufficiently separated so that they can be resolved by the spectrometer. This method is most applicable to the measurement of low-energy beta emitters such as tritium and carbon-14. APHA.609(6), EML LV-539-17(19).

Response: This method is used for determining ${ }^{147} \mathrm{Pm}$ in air filter samples (LA-549-112 for dissolution, LA-613-111 for chemical separation, LA-548-111 for incorporating into scintillation cocktail, and LA-508-121 for liquid scintillation counting). This is also used for determination of ${ }^{14} \mathrm{C}$ (LA-348-101, LA-548-111, and LA-508-121, sequentially) and ${ }^{3} \mathrm{H}$ (LA-218-112, LA-548-111, and LA-508-121, sequentially) in gas samples (WHC 1992a). This method satisfies all of the requirements.

\subsection{Gamma Emitting Radionuclides}

\subsubsection{Method G-1. High Resolution Gamma Spectrometry.}

Principle: The sample is counted with a high resolution gamma detector, usually either a $\mathrm{Ge}(\mathrm{Li})$ or a high purity $\mathrm{Ge}$ detector, connected to a multichannel analyzer or computer. The gamma emitting radionuclides in the sample are measured from the gamma count rates in the energy regions characteristic of the individual radionuclide. Corrections are made for counts contributed by other radionuclides to the spectral regions of the radionuclides of interest. Radiochemical separations may be made prior to counting but are usually not necessary.

Applicability: This method is applicable to the measurement of any gamma emitting radionuclide with gamma energies greater than $20 \mathrm{keV}$. It can be applied to complex mixtures of radionuclides. The samples counted may be in the form of particulate filters, absorbers, liquids or gases. The method may also be applied to the analysis of gaseous gamma emitting radionuclides directly in an effluent stream by passing the stream through a chamber or cell containing the detector. ASTM-3649(9), IDO-12096(18). 
Response: The 222-S Laboratory method uses gamma ray spectroscopy with high resolution germanium detectors and follows procedure LA-508-162 (WHC 1994c). It meets all the requirements explained in Method G-1.

\subsubsection{Method G-2, Low Resolution Gamma Spectrometry.}

Principle: The sample is counted with a low resolution gamma detector, a thallium activated sodium iodide crystal. The detector is coupled to a photomultiplier tube and connected to a multichannel analyzer. The gamma emitting radionuclides in the sample are measured from the gamma count rates in the energy regions characteristic of the individual radionuclides. Corrections are made for counts contributed by other radionuclides to the spectral regions of the radionuclides of interest. Radiochemical separation may be used prior to counting to obtain less complex gamma spectra if needed.

Applicability: This method is applicable to the measurement of gamma emitting radionuclides with energies greater than $100 \mathrm{kev}$. It can be applied only to relatively simple mixtures of gamma emitting radionuclides. The samples counted may be in the form of particulate filters, absorbers, liquids or gas. The method can be applied to the analysis of gaseous radionuclides directly in an effluent stream by passing the gas stream through a chamber or cell containing the detector. ASTM-D-2459(12), EMSL-LV-0539-17(19).

\section{Response: This requirement is not applicable because this method is not used in air filter analysis.}

\subsubsection{Method G-3, Single Channel Gamma Spectrometry.}

Principle: The sample is counted with a thallium activated sodium iodide crystal. The detector is coupled to a photomultiplier tube connected to a single channel analyzer. The activity of a gamma emitting radionuclide is determined from the gamma counts in the energy range for which the counter is set.

Applicability: This method is applicable to the measurement of a single gamma emitting radionuclide. It is not applicable to mixtures of radionuclides. The samples counted may be in the form of particulate filters, absorbers, liquids or gas. The method can be applied to the analysis of gaseous radionuclides directly in an effluent stream by passing the gas stream through a chamber or cell containing the detector.

Response: This requirement is not applicable because this technique is not used in air filter analysis.

\subsubsection{Method G-4, Gross Gamma Counting.}

Principle: The sample is counted with a gamma detector usually a thallium activated sodium iodine crystal. The detector is coupled to a photomultiplier tube and gamma rays above a specific threshold energy level are counted.

Applicability: Gross gamma measurements may be used to measure emissions of specific radionuclides only when it is known that the sample contains a single radionuclide or the identity and isotopic ratio of the radionuclides in the effluent stream are well known. When gross gamma measurements are used to determine emissions of specific radionuclides periodic measurements using Methods G-1 or G-2 should be made to demonstrate that the gross gamma measurements provide reliable emission data. This method may be applied to analysis of gaseous radionuclides directly in an effluent stream by placing the detector directly in or adjacent to the effluent stream or passing an extracted sample of the effluent stream through a chamber or cell containing the detector.

Response: This requirement is not applicable. 
3.5 Counting Methods. All of the methods with the exception of Method A-5 involve counting the radiation emitted by the radionuclide. Counting methods applicable to the measurement of alpha, beta and gamma radiations are listed below. The equipment needed and the counting principles involved are described in detail in ASTM-3648(8).

\subsubsection{Alpha Counting:}

a Gas Flow Proportional Counters. The alpha particles cause ionization in the counting gas and the resulting electrical pulses are counted. These counters may be windowless or bave very thin windows.

-Scintillation Counters. The alpha particles transfer energy to a scintillator resulting in a production of light photons which strike a photomultiplier tube converting the light photons to electrical pulses which are counted. The counters may involve the use of solid scintillation materials such as zinc sulfide or liquid scintillation solutions.

nSolid-State Counters. Semiconductor materials, such as silicon surface-barrier p-n junctions, act as solid ionization chambers. The alpha particles interact which the detector producing electron hole pairs. The charged pair is collected by an applied electrical field and the resulting electrical pulses are counted.

-Alpha Spectrometers. Semiconductor detectors used in conjunction with multichannel analyzers for energy discrimination.

Response: Alpha proportional counters (home-built chambers with EG\&G ORTEC electronics), window-type gas flow proportional counters (some having automatic sample changer), surface-barrier solid-state detectors connected to a multichannel analyzer (MCA) (GENIE system manufactured by Canberra Industries, Inc.) are used for air filter analysis in 222-S laboratory. Laboratory equipment meets the specifications for alpha counting.

\subsubsection{Beta Counting:}

Monization Chambers. These chambers contain the beta-emitting nuclide in gaseous form. The ionization current produced is measured.

- Geiger-Muller (GM) Counters-or Gas Flow Proportional Counters. The beta particles cause ionization in the counting gas and the resulting electrical pulses are counted. Proportional gas flow counters which are heavily shielded by lead or other metal, and provided with an anti-coincidence shield to reject cosmic rays, are called low background beta counters.

ascintillation Counters. The beta particles transfer energy to a scintillator resulting in a production of light photons, which strike a photomultiplier tube converting the light photon to electrical pulses which are counted. This may involve the use of anthracene crystals, plastic scintillator, or liquid scintillation solutions with organic phosphors.

- Liquid Scintillation Spectrometers. Liquid scintillation counters which use two photomultiplier tubes in coincidence to reduce background counts. This counter may also electronically discriminate among pulses of a given range of energy.

Response: Window-type gas flow proportional counter (some having an automatic sample changer) liquid scintillation spectrometers manufactured by Beckman Instruments, Inc., are used for analysis. The 222-S Laboratory counting equipment meets the requirements specified above for beta counting. 


\subsubsection{Gamma Counting:}

-Low-Resolution Gamna Spectrometers. The gamma rays interact with thallium activated sodium iodide or cesium iodide crystal resulting in the release of light photons which strike a photomultiplier tube converting the light pulses to electrical pulses proportional to the energy of the gamma ray. Multi-channel analyzers are used to separate and store the pulses according to the energy absorbed in the crystal.

-High-Resolution gamma Spectrometers. Gamma rays interact with a lithium-drifted (Ge(Li)) or high-purity germanium (HPGe) semiconductor detectors resulting in a production of electron-hole pairs. The charged pair is collected by an applied electrical field. A very stable low noise preamplifier amplifies the pulses of electrical charge resulting from the gamma photon interactions. Multichannel analyzers or computers are used to separate and store the pulses according to the energy absorbed in the crystal.

- Single Channel Analyzers. Thallium activated sodium iodide crystals used with a single window analyzer. Pulses from the photomultiplier tubes are separated in a single predetermined energy range.

Response: High-resolution gamma detectors (high purity Ge detectors for both low and high energies) from EG\&G ORTEC and Princeton Gamma Tech, well-type pure Ge detectors connected to MCA (Canberra's system) are available and used for air filter analysis. The 222-S Laboratory equipment exceeds the requirements for gamma counting specified above.

3.5.4 Calibration of Counters. Counters are calibrated for specific radionuclide measurements using a standard of the radionuclide under either identical or very similar conditions as the sample to be counted. For gamma spectrometers a series of standards covering the energy range of interest may be used to construct a calibration curve relating gamma energy to counting efficiency.

In those cases where a standard is not available for a radionuclide, counters may be calibrated using a standard with energy characteristics as similar as possible to the radionuclide to be measured. For gross alpha and beta measurements of the unidentified mixtures of radionuclides, alpha counters are calibrated with a natural uranium standard and beta counters with a cesium-137 standard. The standard must contain the same weight and distribution of solids as the samples, and be mounted in an identical manner. If the samples contain variable amounts of solids, calibration curves relating weight of solids present to counting efficiency are prepared. Standards other than those prescribed may be used provided it can be shown that such standards are more applicable to the radionuclide mixture measured.

Response: A mixed gamma standard (NIST traceable) emitting various gamma-rays ranging from 59 to $1850 \mathrm{keV}$ is used with vendor-supplied calibration software for constructing efficiency versus energy calibration curves for different geometrical configurations used in gamma analysis. The calibration procedure for gamma ray spectrometer is documented in LQ-508-003 (WHC 1994c). Our calibration procedure meets the EPA criteria for gamma ray spectroscopic analysis.

For calibration of beta detectors for ${ }^{90} \mathrm{Sr} /{ }^{90} \mathrm{Y}$ analysis, procedure LQ-508-002 is used in conjunction with LQ-508-005 (WHC 1992a). It meets the requirements of the EPA-suggested method. A method standard also is used to check the performance and calibration of the detector.

For calibration of alpha/beta proportional counters, procedure LQ-508-002 is carried out. It partially deviates from the EPA requirements. For gross alpha and gross beta 
measurements, our instruments are calibrated with ${ }^{241} \mathrm{Am}$ and ${ }^{60} \mathrm{Co}$ standards, respectively. The reasons for choosing the ${ }^{241} \mathrm{Am}$ standard for alpha calibration are as follows:

- It is commonly found in the PUREX stack air samples.

- Alpha counting efficiency usually is the same for other alpha emitters that also are found in the air stack samples

- The ${ }^{241}$ Am standard also can be checked independently by gamma analysis.

The reason for using the ${ }^{60} \mathrm{Co}$ standard for beta calibration is the lower counting efficiency with ${ }^{60} \mathrm{Co}$ (beta $\max =317 \mathrm{keV}$ ) compared to those with ${ }^{137} \mathrm{Cs}$ (beta $\max =511 \mathrm{keV}$ ) and ${ }^{90} \mathrm{Sr}$ (beta $\max =546 \mathrm{keV}$ ). Consequently, it will generate conservative numbers in our analysis.

The calibration curves relating weight of solids present to counting efficiencies are not done in alpha/beta analysis, but currently are being evaluated.

3.6 Radiochemical Methods for Selected Radionuclides. Methods for a selected list of radionuclides are listed in Table 1. The radionuclides listed are those which are most commonly used and which hove the greatest potential for causing doses to members of the public. For radionuclides not listed in Table 1, methods based on any of the applicable "principles of measurement" described in section 3.1 through 3.4 may be used.

Response: The air samples from the 296-A-1 stack are well characterized. The radionuclides identified ( ${ }^{241} \mathrm{Am},{ }^{239,240} \mathrm{Pu}$ ) are listed in Table 1 of Method 114 (EPA 1991), and are analyzed according to the approved methods given in the table.

3.7 Applicability of Gross Alpha and Beta Measurements to Unidentified Mixtures of Radionuclides. Gross alpha and beta measurements may be used as a screening measurement as a part of an emission measurement program to identify the need to do specific radionuclide analyses or to confirm or verify that unexpected radionuclides are not being released in significant quantities.

Gross alpha (Method A-4) or gross beta (Methods B-2 or B-4) measurements may also be used for the purpose of comparing the measured concentrations in the effluent stream with the limiting "Concentration Levels for Environmental Compliance" in Table 2 of Appendix E. For unidentified mixtures, the measured concentration value shall be compared with the lowest environmental concentration limit for any radionuclide which is not known to be absent from the effluent stream.

Response: This is not applicable because the air effluents from the 296-A-1 stack are well characterized. However, gross alpha and beta analyses for bi-weekly and air samples are routinely performed in the 222-S Laboratory before starting specific radionuclide analyses. Following this practice, the facility can verify a significant release of a radionuclide into the air so corrective actions to minimize its emission can be taken promptly by facility personnel. The gross alpha and beta results from analysis are compared to those listed in the appendix of U.S. Department of Energy (DOE) Order 5400.5 (DOE 1990) for compliance. 


\subsection{Quality Assurance Methods}

Each facility required to measure their radionuclide emissions shall conduct a quality assurance program in conjunction with the radionuclide emission measurements. This program shall assure that the emission measurements are representative, and are of known precision and accuracy and shall include administrative controls to assure prompt response when emission measurements indicate unexpectedly large emissions. The program shall consist of a system of policies, organizational responsibilities, written procedures, data quality specifications, audits, corrective actions and reports. This quality assurance program shall include the following program elements:

4.1 The organizational structure, functional responsibilities, levels of authority and lines of communications for all activities related to the emissions measurement program shall be identified and documented.

Refer to Section 6.2 of WHC-EP-0536-1 for the organizational structure (WHC cd).

4.2 Administrative controls shall be prescribed to ensure prompt response in the event that emission levels increase due to unplanned operations.

Refer to WHC-CM-4-12 (WHC 1992b), Section 1.14, Rev. 1, "Alarm Response and Management." This practice establishes requirements and provides guidance for responding to alarms that are the responsibility of Health Physics (HP).

This practice does not apply to alarms intentionally activated according to approved procedures, (e.g., functional test, source test). Facility specific procedures or desk instructions based on those procedures may be provided by the Area HP managers to address alarm systems specific to each facility. Refer to WHC-CM-4-12, Section 2.1, Rev. 0, "Radiological Problem Reporting Program." The purpose of the Radiological Problem Report program is to provide a documented record of observed radiological problems, a mechanism for reporting these problems to management for action, a capability to track and monitor the progress of the planned corrective actions, and a database for assessing trends in radiological program performance and needed actions.

Refer to WHC-CM-4-12, Section 12.1, Rev. 1 "Emergency Response." An emergency is a sudden, unexpected event that requires immediate response to mitigate impacts to people, property, or the environment. When radioactive material is involved, HP plays a major role in evaluating, controlling, and recovering from the event. To be able to perform this function HP personnel receive training to respond to a variety of emergency situations. The HP procedures are written to provide guidelines to respond to emergencies. Together, the training and written procedure detail the HP Emergency Response Program. 
Emergency Response- The HP personnel are, in many situations, the first to respond to a radiological emergency. The ability to assess and evaluate the situation and take immediate steps to minimize the effects of the event is crucial for controlling the emergency. HP personnel must use their training and experience to make good decisions during the initial response to an emergency.

An emergency response may be initiated by personnel observing the event, alarms, the Patrol Operation Center, or the Emergency Control Center(s) once they are manned. For a planned response, HP personnel shall be in teams of at least two. Out of necessity (e.g., backshift response), one member could be an operations person or other emergency service person such as fire or patrol. A rapid response is required; however, no undue risks should be taken nor should employee personnel safety be compromised. The type of emergency determines the level of planning for HP response. For example, a CAM alarm or a small radioactive spill requires little planning for the initial response. However, when an emergency causes a facility evacuation, preplanning (e.g., stay time, entry route, etc.), and approval of the building/facility emergency director is necessary for a re-entry.

Although HP personnel respond to an emergency using basic guidelines, an area/facility may have specific procedures that have priority over these guidelines.

Refer to WHC-IP-0718 (WHC 1993d), Section ER-02, Rev. 1, "Air Sampling Checklist." This checklist establishes the instruction and guidelines for air sampling in an emergency situation.

Refer to WHC-IP-0718, Section ER-02, Rev. 1, "Plume Tracking Checklist." This checklist establishes the instruction to track a plume created from a radioactive material release to the environment.

Refer to WHC-IP-0718, Section ER-02, Rev. 1, "General Emergency Response Guidelines and Checklists." This procedure provides the Health Physics technician with checklists and instruction for response to various radiological emergencies.

Refer to WHC-IP-0263-202A (WHC 1992c), Westinghouse Hanford Company Emergency Plan for PUREX Facility. This document provides instructions for many types of emergencies, including excessive releases of radioactivity via the stacks.

Refer to WHC-CM-5-9 (WHC 1992b), Section 2.3, Rev. 3, "PUREX/UO 3 Plant Occurrence Categorization, Notification, and Reporting." This procedure provides instructions for notification and reporting of specific events including environmental releases and related events. 
4.3 The sample collection and analysis procedures used in measuring the emissions shall be described including where applicable:

4.3.1 Identification of sampling sites and number of sampling points, including the rational for site selection.

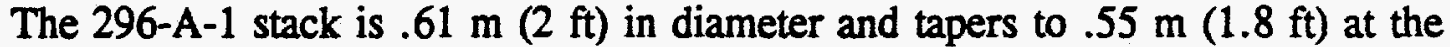
top. The record sampling site is located at a height of $10.4 \mathrm{~m}(34 \mathrm{ft})$ above the base. There are a total of three sampling sites and three sampling probes.

The elevations of the sample ports are $10.4,11.6$, and $12.8 \mathrm{~m}(34,38$, and $42 \mathrm{ft})$ above base, which is the location of the last major flow disturbance in the stack. The sample ports are, therefore, approximately 17, 19, and 21 diameters downstream of the last major disturbance.

The stack is $18.9 \mathrm{~m}$ ( $62 \mathrm{ft}$ ) from base, or 31 diameters. The sample ports are, therefore, approximately 14,12 , and 10 diameters upstream of the next major flow disturbance.

The sites were chosen to provide representative sampling of the effluent and to comply with ANSI N13.1-1969 (ANSI 1969). The lowest sample port was chosen as the location of the record sample probe to minimize the length of sample line in accordance with ANSI N13.1-1969. These sample points also meet the criteria of 40 CFR 60, Appendix A, Method 1 (EPA 1992).

\subsubsection{A description of the sampling probes and representativeness of the samples.}

The sampling probes for the record sampler and the Alpha CAM are identical, and are mounted in the horizontal plane at the 14.0- and 16.5-m (46- and 54-ft) level respectively. Note: For information purposes related to this study, the sampling ports have been numbered $1,2,3$, and 4 .

The sampling probe consists of four nozzles branching from a single delivery line and is made entirely of 304 stainless steel tubing (drawing H-2-75571, WHC 1991). At the inlet, each port is tapered to a knife edge with a 15-degree angle. The first port, located at the center of the stack, is made of .79-cm (5/16-in.) OD, .089-cm (0.035-in.) wall tube. The inlet has a vertical section of $4.76 \mathrm{~cm}(1.875 \mathrm{in}$.), followed by a radius bend of 1.875 leading into the sample delivery line. The second port, located $18.4 \mathrm{~cm}(7.25 \mathrm{in}$.) from the center of the stack, is made of $1 / 8$ Schedule 40 s pipe [.68-cm $(0.269$-in.) ID]. The inlet has a vertical section of $6.4 \mathrm{~cm}(2.5 \mathrm{in}$.) followed by a radius bend of 2.5 leading into the sample delivery line. The third port, located $23.97 \mathrm{~cm}(9.438 \mathrm{in}$.) from the center of the stack, is made of .95-cm (3/8-in.) OD, .124-cm (0.049-in.) wall tube. The inlet, has a vertical section of $5.7 \mathrm{~cm}(2.25 \mathrm{in}$.) followed by a radius bend of 2.25 , leading into the sample delivery line. The fourth port, located $28.42 \mathrm{~cm}(11.188 \mathrm{in}$.) from the center of the stack, is made of $1 / 4$ Schedule $80 \mathrm{~s}$ pipe [.76 cm $(0.302 \mathrm{in})$.$] . The inlet, has a vertical section of 8.3 \mathrm{~cm}(3.25 \mathrm{in}$.$) ,$ 
followed by a radius bend of 3.25 , leading into the sample delivery line. The outer sampling line is made of $1.9-\mathrm{cm}(3 / 4-\mathrm{in}$.$) OD, .27-cm (0.109-in.) wall$ tube. The inlet ports with different cross sectional areas are centered approximately in four equal annular areas. The use of an isokinetic 4-point probe located more than 15 duct diameters downstream of the last major flow disturbance is believed to achieve representative sampling (stack and sample flow rates are checked daily to ensure near isokinesis of $\pm 10 \%$ ).

4.3.3 A description of any continuous monitoring systems used to measure emissions, including the sensitivity of the system, calibration procedures and frequency of calibration.

This requirement is not applicable--emissions are not monitored continuously for compliance demonstration.

4.3.4 A description of the sample collection systems for each radionuclide measured, including frequency of collection, calibration procedures and frequency of calibration.

The sample is removed continuously from the effluent stream by the probe described in Section 4.3.2. The sample then flows through the sample line and the particulates are collected on a sample filter. The sample filters are replaced bi-weekly, and evaluated for gross alpha and gross beta activities by laboratory analysis. The filter media is then composited for quarterly analysis of specific radionuclide concentrations.

The CAM loop collects particulate matter in a similar fashion to that of the record sampler, but the CAM monitors for elevated radioactivity on the filter. This instrument provides process control and backup capability for the record sampler. The CAM is calibrated every six months.

4.3.5 A description of the laboratory analysis procedures used for each radionuclide measured, including frequency of analysis, calibration procedures and frequency of calibration.

Response:

- Total alpha/total beta activity is determined by procedure LA-508-110 or LA-508-114 on bi-weekly samples, and occasionally on daily air samples, per collection point. The calibration procedure is documented in LQ-508-002. It is done only when deemed necessary by a responsible scientist. The counting system is recalibrated only in case of (1) major repairs or adjustments to the power supply or detector or (2) calibration shift as indicated by the instrument control standards. The performance of the counting systems is checked by running the instrument control standards $\left({ }^{147} \mathrm{Pm}\right.$ for low-energy beta, ${ }^{60} \mathrm{Co}$ for mid-energy beta, ${ }^{137} \mathrm{Cs}$ for high-energy beta, and ${ }^{241} \mathrm{Am}$ for alpha activity) separately. When a batch of air filter samples are run, all the performance standards and the background (for counting frequency refer to LO-150-115) are also run with 
it. To verify that the counting system is working properly, the standard values from analysis should fall within the administrative limits set according to appropriate quality assurance program plans.

- The 222-S laboratory method for analysis of alpha emitters ${ }^{241} \mathrm{Am},{ }^{238} \mathrm{Pu}$, and ${ }^{239,240} \mathrm{Pu}$ ) involves various steps (LA-549-112 for dissolution, LA-943-123 for chemical separation, LA-542-101 for electrodeposition, and LA-508-161 for final alpha spectrometry). The analysis of alpha emitters is done quarterly on bi-weekly air filter samples. The energy resolution and calibration of the AEA system over the energy range of 4 to $6 \mathrm{MeV}$ are checked once a month by the preventive maintenance procedure 2S18006. Efficiency calibration of the AEA is not needed in our analysis method because direct comparison of the sample with recoveries of the tracers $\left({ }^{23} \mathrm{Am}\right.$ and $\left.{ }^{236} \mathrm{Pu}\right)$ is made to determine the activities of the radionuclides present in the sample. To carry out the sample analysis, AEA system performance is checked once every 24 hours for alpha energy shift with a certified mixed alpha source standard. Each alpha energy peak identified in the standard must fall within administratively assigned channels $( \pm 10)$ on the MCA. For counting frequency of performance check standards, procedure LO-150-115 is referred to. The recovery of the radionuclides and the calibration of the system are checked on a batch basis by running a method standard under the identical conditions as the sample.

- The content of the 222-S Laboratory's procedures, test plans, supporting documents, and drawings provide a sufficient level of detail to allow trained personnel to produce quality results safely. Laboratory procedures are controlled as required by WHC-CM-5-4, Section 5.4, "Analytical Laboratory Procedures." The specific content of laboratory procedures is defined by its author, based on accepted methods such as 40 CFR 61 , Appendix B, Method 114 (EPA 1991). The content must be agreed to by the peer and technical reviewers. While authors are responsible for the specific content of their procedures, they address the topics below.

Summary - MANDATORY - A short description or abstract of the procedure that contains enough information to distinguish it from other procedures.

Applications - MANDATORY - This section defines the scope and purpose of the specific procedure. This section may be combined with the following element under the title "Applications and Limitations."

Limitations - MANDATORY - This section briefly describes those areas in which the procedure is not applicable. A statement of accuracy and precision will be given where appropriate. 
Quality Control Protocol - These procedures are used to support environmental projects that have specific quality control requirements. For these procedures, the source of the quality control requirements will be identified. The samples or project that this element applies to will be identified. The following information is typical of quality control requirements: frequency and type of calibration, reagent blank analysis, spike sample analysis, and duplicate sample analysis.

Impact Level Identifier - MANDATORY - An impact level will be identified for each procedure following WHC-CM-1-3, MRP 5.43, with a brief basis of determination statement. This MRP lists several descriptive paragraphs delineating what constitutes an Impact Level 1, 2, 3, or 4 activity. The following parts of MRP 5.43 cover most analytical laboratory procedures.

1. Section 5, paragraph 6, part c., Impact Level 3 - work authorization documentation associated with work involving occupational hazards not covered by approved procedure, such as Operational Safety Assessments, Radiation Work Permits, or Industrial Safety Standards.

2. Section 5, paragraph 6, part c., Impact Level 4 - Documentation for any activity not classified as Impact Level 1,2 , or 3.

The laboratories' procedures are usually specific to one activity. These activities are well defined using common scientific instrumentation and equipment operated in an acceptable manner. The chemicals and materials used are normally small quantities with limited potential for environmental or personnel safety impact. In general, the equipment used in the laboratory is not classified as Safety Class 3 or higher.

Safety - MANDATORY - The procedure must identify applicable safety hazards.

The following documents identify Westinghouse Hanford Company (Westinghouse Hanford) safety requirements:

- WHC-CM-4-3, Volume 1-3, Industrial Safety

- WHC-CM-4-10, Radiation Protection

- WHC-CM-4-15, Radiation Work Requirements and Work Permits Manual

- WHC-CM-4-29, Nuclear Criticality Safety.

Supporting document WHC-SD-CP-LB-003, Safety in the Analytical Laboratory, is the laboratory general safety document. The authors must review safety requirements and include safety warnings appropriate to the actions directed by the procedure. 
Reagents - If the procedure requires analytical reagents, a list of reagents will be provided. The material safety data sheet number will be placed in brackets by each chemical name. Reagent makeup, storage container requirements, unique storage needs, shelf-life requirements, special labeling, and special preparation steps will be included. Special notations for any known or suspected carcinogen as listed on WHC-CM-4-3, Volume 2, Table 1, "WHC Master Carcinogen List," will be made on the reagent list.

Reagent preparation described fully in other current Westinghouse Hanford documentation may be included by reference.

Equipment - Special equipment needs will be listed. Standard hood or glovebox equipment is assumed to be available at the work station and does not need to be listed. The fabrication of off-standard equipment will be referenced or described in this section.

Procedure Steps - MANDATORY - A step-by-step description of operations necessary to perform the task will be presented in a logical and sequentially numbered order or an assignment of responsibilities. Caution and Warning notations will be included for the applicable safety hazard before the action is described. Steps with potential for criticality specification violation will be identified. Explanatory notes may be included for clarification of process.

Calculations - Calculations required to complete the work will be described in this section. Examples with sample values may be included. All combined factors will be fully described and units noted.

Calibrations - When calibrations are required, a description of how to carry out required calibrations will be given.

Discussion - This section provides a discussion of the theoretical aspects of the procedure. Brief identification of unique characteristics and interfaces to aid in troubleshooting may be included.

References - A reference list of published information to provide technical basis for the procedure may be included.

The mandatory topics are addressed in both procedures. However, the laboratories have technical, analytical, and administrative procedures. Non-mandatory topics are included if appropriate to the activity covered by the procedure.

The calibrations of all laboratory instruments are controlled by the Laboratory Instrument Calibration Control System (LICCS) (WHC-CM-5-4, Section 8.2). 
The LICCS documents the requirements for and the performance of calibration activities for each analytical instrument or measurement device.

4.3.6 A description of the sample flow rate measurement systems or procedures, including calibration procedures and frequency of calibration.

The sample collection and monitoring system consists of a record sampler and one Alpha CAM. The record sample is considered the regulatory portion of the system for reporting the amount and concentration of radionulides released to the environment. The generated reports are forwarded to all appropriate organizations and agencies. The CAM is considered the operational safety device and is set to alarm (located in dispatcher's office) if emissions are detected above present levels. The sampling system is designed with two identical sampling probes mounted in the horizontal plane at the 14.0- and 16.5-m (46- and 54-ft) level for the record sampler and Alpha CAM respectively.

The sample flow rate is measured and regulated by instruments located downstream of the sample collection filter and CAM. The record sample loop passes through a flow transmitter, a flow regulator (flow control valve), a flow switch (flow alarm switch), a vacuum gauge, and a vacuum pump. The flow transmitter will send an electrical signal to the flow indicator control and the totalizer. The flow rate regulator is provided to maintain a constant flow rate through the collection filter assembly to compensate for filter-loading effects. At least once a day an employee adjusts the FIC-V28A-2-1 to ensure near isokinesis $( \pm 10 \%)$. The audible and visible alarm signals that indicate low flow rates for record sampler are provided remotely in the dispatcher's office (refer to drawing H-2-75568, WHC 1991). The calibration procedures and frequencies for the record sampler are summarized in Table 1. 
Table 1. Calibration Procedures and Frequencies for the Record Sampler (Sample Flow Measurement Devices).

\begin{tabular}{|l|c|c|c|}
\hline \multicolumn{1}{|c|}{ Component } & Procedures & CBRS* & Frequency \\
\hline $\begin{array}{l}\text { Flow transmitter } \\
\text { (FT-V28A-2-1) }\end{array}$ & PSCP-6-153 & V28A2-2 & 6 month \\
$\begin{array}{l}\text { Flow alarm switch } \\
\text { (FAS-V28A-3-1) } \\
\begin{array}{l}\text { Flow indicator control } \\
\text { (FIC-V28A-2-1) }\end{array}\end{array}$ & PSCP-6-029 & V28A3-1 & 6 month \\
$\begin{array}{l}\text { Flow integrator } \\
\text { (FQ-V28A-2-1) }\end{array}$ & PSCP-1-008 & V28A2-3 & 6 month \\
\hline
\end{tabular}

* Computer Based Recall System

The CAM loop differs only in that the sight flow indicator is an integral part of the CAM itself and that there is no flow totalizer. All other flow measurements, regulations, and monitoring are identical to that of the record sampler loop. The audible and visible alarm signals that indicate low flow rates for the CAM are provided remotely in the dispatcher's office. The Alpha count recorder is located in the central control room. The calibration procedures and frequencies for Alpha CAM are summarized in Table 2.

Table 2. Calibration Procedures and Frequencies for Alpha Continuous Air Monitor Sampler (Sample Flow Measurement Devices).

\begin{tabular}{|l|c|c|c|}
\hline \multicolumn{1}{|c|}{ Component } & Procedures & CBRS* & Frequency \\
\hline $\begin{array}{l}\text { Flow alarm switch } \\
\text { (FAS-V29A-3-1) }\end{array}$ & PSCP-6-029 & V29A3-1 & 12 month \\
$\begin{array}{l}\text { Continuous air } \\
\text { monitor/rotameter } \\
\text { (RAN-V29A-1-1) }\end{array}$ & PSCP-3-083 & YA242-A & 6 month \\
\hline
\end{tabular}

*Computer Based Recall System 
Alternative vacuum pumps are provided for the system. Failure annunciation (low flow rates) is provided and checked periodically in the dispatcher's office to demonstrate operability.

4.3.7 A description of effluent flow rate measurement procedures, including frequency of measurements, calibration procedures and frequency of calibration.

An Annubar probe (multipoint probe) continuously measures the flow through the stack at the $15.2-\mathrm{m}(50-\mathrm{ft})$ level. The annubar probe senses a total pressure through the velocity ports and a low pressure through the downstream ports. From their differential pressure, the flow transmitter sends the signal to the flow integrator and the totalizer. The total flow is recorded on a digital integrator in the central control room.

Flow measurements are accomplished quarterly following Procedure 7-GN-56 using a traverse pitot tube. There are 2 ports spaced $90^{\circ}$ apart located $4.6 \mathrm{~m}$ $(15 \mathrm{ft})$ above the sampling probe location on the stack. These locations are at 26.5 duct diameters downstream and 4.5 duct diameters upstream of any flow disturbances. These measurements are taken in each port at 10 equal annular traverse points ( 20 in all). The calibration procedures and frequencies for stack flow measurement devices are summarized in Table 3.

Table 3. Calibration Procedures and Frequencies for Stack Flow Measurement Devices.

\begin{tabular}{|l|c|c|c|}
\hline \multicolumn{1}{|c|}{ Component } & Procedures & CBRS* & Frequency \\
\hline $\begin{array}{l}\text { Flow transmitter } \\
\text { (FT-V21-10-1) }\end{array}$ & PSCP-6-032 & V2110-2 & 6 month \\
$\begin{array}{l}\text { Flow integrator } \\
\text { (FQ-V21-10-1) }\end{array}$ & PSCP-1-008 & V2110-8 & 6 month \\
$\begin{array}{l}\text { Flow alarm switch } \\
\text { (FAS-V21-10-1) }\end{array}$ & PSCP-4-001 & V2110-5 & 6 month \\
\hline
\end{tabular}

${ }^{*}$ Computer Based Recall System

4.4 The objectives of the quality assurance program shall be documented and shall state the required precision, accuracy, and completeness of the emission measurement data including a description of the procedures used to assess these parameters.

The accuracy of all analyses is checked using percent recovery. The evaluation of blind or known check standards provides the percent recovery. 
For both blind and known check standards, percent recovery is calculated by the following equation:

$$
P=100 \cdot \frac{R}{S_{t}}
$$

Where:

$\mathbf{P} \quad=\quad$ Percent recovery

$\mathrm{R}=$ Measured or recovered analyte concentration in the check standard

$S_{t}=$ Concentration of analyte in the check standard.

The laboratories do not use manual W. A. Shewhart control charts (Shewhart 1931). The Laboratory Measurement Control System (LMCS) is a software package designed for support of management quality control decisions. Each analytical measurement system has different control parameter requirements based on the use of specific standards. The LMCS program provides a performance versus limits control chart for each standard. The average percent recovery $(\overline{\mathrm{P}})$ or 100 percent, depending on the method, marks the center of the limit. The upper and lower boundaries of the limits are multiples of the standard deviation(s) of the average percent recovery. The laboratory manager approves the LMCS limits, defined as $\bar{P} \pm n s$, where $n$ is a positive number. The values for $\overline{\mathrm{P}}$ and $s$ are performance based. In general, management sets the warning limits at $2 \mathrm{~s}$ and the control limits at $3 \mathrm{~s}$ or their equivalent.

When the LMCS identifies an out-of-control method, it automatically initiates corrective action. The system issues an off standard condition report (ESCHEWER). The scientist in charge of the method must discover and resolve the problem to close out the ESCHEWER. Until the ESCHEWER has been closed, personnel can not perform any analyses by this method. After the scientist has resolved the problem, personnel evaluate all analyses performed since the last in-control point.

The laboratories assess precision by examining the results from split samples or laboratory duplicates. Percent relative difference measures the precision of analyses. Percent relative difference is computed by the following equation:

$$
R D=100 \cdot \frac{S_{d}}{X}
$$


Where:
$\mathrm{RD}=$ Percent relative difference
$S_{d}=$ The standard deviation estimate of the duplicate data set
$\mathrm{X}=$ The arithmetic mean (average) of the duplicate data set.

The initial QA objective for completeness of analyses in the laboratories is 90 percent. This means that the goal is to produce usable analytical data for a minimum of 90 percent of the analyses requested on all samples submitted to the laboratory. The laboratory evaluates actual performance against the 90 percent objective. If the laboratory performance drops below this limit, management initiates corrective action. This action shall identify and correct those activities within the laboratory that have caused the drop in performance. The objectives are documented in the Environmental Protection Quality Assurance Project Plan (WHC 1992d).

4.5 The quality control program shall be established to evaluate and track the quality of the emission measurement data against preset criteria. The program should include, where applicable, a system of replicates; spiked samples; split samples; blanks; and control charts. The number and frequency of such quality control checks shall be identified.

The samples analyzed under this program consist of mounts made from preparation of stack filters. Each sample collection point produces only one sample, which is sent to the laboratory for analysis. No replicate samples are available. Repeat measurement of individual samples is made at the discretion of the scientist in charge.

As a type of process-control sample, stack filters are not subject to matrix effects and radionuclide spikes are not used. However, tracer elements ${ }^{243} \mathrm{Am}$ and ${ }^{236} \mathrm{Pu}$ or ${ }^{242} \mathrm{Pu}$ support the analysis of ${ }^{241} \mathrm{Am},{ }^{238} \mathrm{Pu}$, and ${ }^{239,240} \mathrm{Pu}$ in the quarterly composite of bi-weekly filter samples.

The laboratory does not split samples. There is no guarantee that the distribution of material on the filter will be homogenous. Because of this, no subsampling procedure, such as splitting, can assure that two representative portions are produced. Also, splitting the sample in effect dilutes the sample, which would adversely affect the method detection limits.

Formal blanks are not available for these analysis. However, before the analysis of a batch of samples, the background of the counting instrument is checked. This background check is made on each planchet and planchet holder.

Control charts and standards used in support of these analysis are described in Section 4.4 above. 
4.6 A sample tracking system shall be established to provide for positive identification of samples and data through all phases of the sampling collection, analysis, and reporting system. Sample handling and preservation procedures shall be established to maintain integrity of the samples during collection, storage, and analysis.

\section{Refer to Section 6.2.1 of WHC-EP-0536-1.}

4.7 Periodic internal and external audits shall be performed to monitor compliance with the quality assurance program. These audits shall be performed in accordance with written procedures and conducted by personnel who do not have responsibility for performing any of the operations being audited.

\section{Refer to Section 8.0 of WHC-EP-0536-1.}

4.8 A corrective action program shall be established including criteria for when corrective actions will be taken and who is responsible for taking the corrective action.

\section{Refer to Section 9.0 of WHC-EP-0536-1.}

4.9 Periodic reports to responsible management shall be prepared on the performance of the emission measurements program. These reports should include assessment of the quality of the data, results of audits, and description of corrective actions.

\section{Refer to Section 10.0 of WHC-EP-0536-1.}

4.10 The quality assurance program should be documented in a quality assurance project plan which should address each of the above requirements.

The quality assurance program addressing stack 296-A-1 will be documented in a future quality assurance project plan. 
This page intentionally left blank. 


\section{REFERENCES}

ANSI, 1969, Guide to Sampling Airborne Radioactive Materials in a Nuclear Facility, ANSI N13.1, American National Standards Institute, Washington, D.C.

DOE, 1990, Radiation Protection of the Public and the Environment, DOE Order 5400.5, U.S. Department of Energy, Washington D.C.

EPA, 1991, National Emission Standards for Hazardous Air Pollutants Requirements, Title 40, Code of Federal Regulations, Part 61, U.S. Environmental Protection Agency, Washington, D.C.

EPA, 1992, "Standards of Performance for New Stationary Sources," Title 40, Code of Federal Regulations, Part 60, U.S. Environmental Protection Agency, Washington, D.C.

Napier, B. A., R. A. Peloquin, D. L. Strenge, and J. V. Ramdsell, 1988, GENII - The Hanford Environmental Radiation Dosimetry Software System, PNL 6584, Vol. 1-3, Pacific Northwest Laboratory, Richland, Washington.

RL, 1993, Calendar Year 1992 Radionuclide Air Emissions Report for the Hanford Site, DOE/RL-93-36, U.S. Department of Energy, Richland Field Office, Richland, Washington.

WHC, 1990, Westinghouse Hanford Company Effuent Discharges and Solid Waste Management Report for Calendar Year 1989: 200/600 Areas, WHC-EP-0141-2, Westinghouse Hanford Company, Richland, Washington.

WHC, 1991, Drawings, Westinghouse Hanford Company, Richland, Washington.

- H-2-75568, DWG List/Engineering Flow Diagram PR Room Stack MON - H-2-75570, ELEC/INSTM Plan Elevations \& DET PR Stack Monitoring - H-2-75571, ELEC/INSTM Installation Details PR Room Stack Monitor

WHC, 1992a, Laboratory Procedures, Westinghouse Hanford Company, Richland, Washington.

- LA-218-112, Tritium analysis on Silica gel by Liquid Scintillation Counting

- LA-220-103, Strontium-89, 90 and/or Strontium-89 and 90 from Leachates of Soil, Vegetation, Air Filters, and Other Solid Samples

- LA-348-101, Carbon-14 by Distilling and Liquid Scintillation Counting

- LA-508-110, Operation of the Tennelec LB-5500 Alpha/Beta Counting System

- LA-508-111, Operation of the Tennelec LB-1000 Alpha/Beta Detectors $(9,10$, 11 , and 12) 
- LA-508-114, Operation of the gamma products alpha beta counting system using PC control

- LA-508-121, Operation of the Beckman Liquid Scintillation Counters

- LA-548-111, Preparation of Mounts for Liquid Scintillation Counting

- LA-549-112, Dissolution of Versapor Type Filers

- LA-613-111, Determination of Promethium-147 in Effluent Wastes Samples by Solvent Extraction and Liquid Scintillation Counting

- LA-925-107, Uranium by Laser Induced Kinetic Phosphorescence Analyzer

- LA-943-123, Separation of Pu and Am by lon Exchange,

- LO-150-115, Instrument Standards Counting Frequency--222-S Counting Room

- LO-150-133, Processing Record Stack and Red Bordered Emergency Air Samples

- LQ-508-002, Calibration Guidelines for Window Type Gas Flow Alpha/Beta Proportional Counters

- LQ-508-005, Calibration of Beta Detector for Sr-90 and Y-90

- WHC-SD-CP-LB-003, Safety in the Analytical Laboratory

WHC, 1992b, Manuals, Westinghouse Hanford Company, Richland, Washington.

- WHC-CM-1-3, Management Requirements and Procedures

- WHC-CM-4-2, Quality Assurance Manual

- WHC-CM-4-3, Industrial Safety

- WHC-CM-4-10, Radiation Protection

- WHC-CM-4-12, Health Physics Practices Manual

- WHC-CM-4-15, Radiation Work Requirements and Work Permits Manual

- WHC-CM-4-29, Nuclear Criticality Safety

- WHC-CM-5-4, Analytical Chemistry Services Laboratories - Operating Instructions

- WHC-CM-5-9, PUREX/UO ${ }_{3}$ Plant Occurrence Categorization, Notification, and Reporting

WHC, 1992c, Westinghouse Hanford Company Emergency Plan for PUREX Facility, WHC-IP-0263-202A, Westinghouse Hanford Company, Richland, Washington.

WHC, 1992d, Quality Assurance Project Plan for Radioactive Airborne Emissions Data Compilation and Reporting, WHC-EP-0528, Westinghouse Hanford Company, Richland, Washington.

WHC, 1993a, Airflow Capacity and Distribution Tests, Facilities Maintenance support Services Maintenance Procedure 7-GN-56, Rev 2 Change A, Westinghouse Hanford Company, Richland, Washington.

WHC, 1993b, Final Report on Fiscal Year 1992 Activities for the Environmental Monitors Line-Loss Study, WHC-EP-0680, Westinghouse Hanford Company, Richland, Washington. 
WHC, 1993c, Quality Assurance Program Plan for Radionuclide Airborne Emissions Monitoring, WHC-EP-0536-1, Westinghouse Hanford Company, Richland, Washington.

WHC, 1993d, Health Physics Procedures Manual, WHC-IP-0718, Westinghouse Hanford Company, Richland, Washington.

WHC, 1994a, Plutonium-Uranium Extraction Plant Product Removal (296-A-1) Stack Potential Dose Determination, WHC-SD-CP-TI-188, Westinghouse Hanford Company, Richland, Washington.

WHC, 1994b, Determination of Effluent Flow for Large Stacks, Maintenance Engineering Services Maintenance Procedure, PROC. NO. 1202, Westinghouse Hanford Company, Richland, Washington.

WHC, 1994c, Laboratory Procedures, Westinghouse Hanford Company, Richland, Washington.

- LA-508-161, Alpha Energy Analysis using the Canberra Jupiter Systems

- LA-508-162, Gamma Energy Analysis on the Canberra Jupiter System

- LA-542-101, Electrodeposition of Actinides

- LQ-508-003, Calibration of the Jupiter Gamma Energy Analysis Systems 


\section{DISTRIBUTION}

\section{Number of Copies}

ONSITE

R. W. Bailey

S5-66

W. E. Davis

H6-20

L. P. Diediker

T1-30

T. P. Frazier

T1-30

K. A. Hadley

R3-56

D. G. Hamrick

S6-15

D. G. Harlow

S6-19

D. L. Johnson

S6-17

J. Lohrasbi (10)

S6-17

J. J. Luke

H6-25

R. V. Skinner

S6-21

D. L. Wiegand

S6-17

C. D. Wollam (3)

S6-17

Document Processing and Distribution (2)

L8-15

Information Release Administration (3)

R1-05 